\title{
Normas de aplicación directa y protección del paisaje en la Ley de Cantabria 2/2001 de 25 de junio. ¿Límites a las discrecionalidad de la administración o conceptos jurídicos indeterminados?
}

\author{
José Luis De Vicente González \\ Secretario e Interventor de Administración Local \\ Ayuntamiento de Torrelavega
}

Sumario. 1. INTRODUCCIÓN. 2. ANTECEDENTES NORMATIVOS. 2.1. El artículo 138 a) del RD Leg 1/92 de 26 de junio. 2.2. El artículo 138 b) del RD Leg 1/92 de 26 de junio. 3. FINALIDAD DE LAS NORMAS DE APLICACIÓN DIRECTA. 4. APLICACIÓN DE LA NORMA, DISCRECIONALIDAD Y CONCEPTO JURÍDICO INDETERMINADO. 4.1. Las normas de aplicación directa como ordenación inmediata de la Ley. 4.2. El Planeamiento como delimitador de la zona de incertidumbre de las normas de aplicación directa. 5. LAS NORMAS DE APLICACIÓN DIRECTA EN LA LOTRUSC. 5.1. Protección del entorno cultural. 5.2. Protección del paisaje. 6. NORMAS DE APLICACIÓN DIRECTA Y AUTONOMÍA MUNICIPAL. 7. CONCLUSIONES

\section{INTRODUCCIÓN}

La Ley de Cantabria 2/2001, de 25 de junio, de Ordenación del Territorio y del Régimen Urbanístico del Suelo, en adelante LOTRUSC, ha recogido como uno de sus principios inspirados el de sujeción a la cultura jurídica urbanística desarrollada en nuestro país con base en la Ley del Suelo de $1956^{1}$, no es de extrañar en consecuencia que la misma formule como

\footnotetext{
${ }^{1}$ La Ley en su preámbulo señala expresamente que:

La cultura jurídico-urbanística es también un condicionante obligado a la competencia legislativa autonómica. En este caso, no se trata de la imposición de las derivaciones de una competencia ajena, sino de una consecuencia de la prudencia.

Y es que, desde la Ley del Suelo de 12 de mayo de 1956, con la que se puede decir que nace verdaderamente el Derecho Urbanístico Español, se ha ido consolidando poco a poco y no sin dificultades un haz de conceptos, una suma de presupuestos, un lenguaje y un modo de encarar el fenómeno urbano. No conviene, por tanto, sin muy buenas razones y por el simple argumento de la originalidad, prescindir del bagaje cultural que una disciplina el Derecho Urbanístico ha generado desde hace ya cuarenta años. La originalidad aquí no es necesariamente un dato positivo. Hay que conservar en lo posible los valores de la primitiva Ley de 1956, que no hicieron sino perfeccionarse en sus posteriores modificaciones. $Y$ entre esos valores está el puramente metodológico y el del propio lenguaje, que en el mundo del Derecho es esencial porque proporciona seguridad.
} 
un elemento mas de su estructura normativa la existencia de las normas de aplicación directa que establecen, como veremos, un claro límite a la libertad de decisión del planificador, pues según el preámbulo de la Ley cántabra:

La flexibilidad de contenidos del planeamiento general resulta compensada con la previsión de normas protectoras más intensas, las normas de aplicación directa - que se imponen por sí mismas, con o sin Plan, y que, en todo caso, condicionan a éstos-y los estándares urbanísticos —que, aunque no son de aplicación directa, se imponen también al planeamiento municipal-. Ahi queda resguardado y protegido el ámbito o núcleo mínimo legal, el denominador normativo común a partir del cual el planificador municipal podrá ampliar las exigencias, pero no reducirlas.

Estas normas, se afirma en la Ley cántabra, se imponen tanto si existe Plan como si no lo hay y en consecuencia, además de cumplir la función tradicionalmente atribuida a las mismas, son límites infranqueables al planificador que debe observarlas en todo momento, no como derecho supletorio o con carácter subsidiario, sino como principios que presiden y se imponen sobre todas las decisiones de planificación y ejecución.

Centraremos nuestra atención en una de las normas de aplicación directa como es la relativa a la protección del paisaje en la LOTRUSC, cuyas conclusiones son en gran parte extrapolables al resto de las normativas autonómicas, por lo que como paso obligatorio se estima preciso analizar cuales son estas normas y cuáles sus antecedentes mas inmediatos a fin de poder determinar su régimen jurídico y la función que cumplen en nuestro ordenamiento.

\section{ANTECEDENTES NORMATIVOS}

Como es de esperar tras la declaración de sujeción a la cultura jurídica urbanística que realiza el legislador cántabro, los antecedentes de protección del paisaje como norma de aplicación directa recogida en la norma autonómica deben encontrarse en los anteriores textos normativos estatales reguladores del régimen urbanístico del suelo.

Así, la Ley de 12 de mayo de 1956, sobre Régimen del Suelo y Ordenación Urbana, recogía las normas de aplicación directa en los artículos 59 y 60, encuadradas en el capítulo Cuarto relativo a las Normas de ordenación complementaria y subsidiarias del planeamiento, teniendo por objeto el primero de ellos regular la construcción en lugares inmediatos a las carreteras y el segundo, que puede calificarse como antecedente inmediato del artículo 73 del Texto Refundido de 1976 que paso posteriormente a 
ser el artículo 138 del RD Leg 1/1992, de 26 de junio, el establecimiento de la obligación de armonización de las construcciones y la conservación del paisaje.

Ciertamente su interpretación, ajustada al criterio temporal en que surge, no puede ser equiparada a la actual, lo que se puso de manifiesto en declaraciones jurisprudenciales como las recogidas en la STS de 3 de marzo de 1980 (RJ 1980\2028)

Para Enrique Porto Rey la exigencia de adaptación de las construcciones al ambiente en que estuvieran situados, y que es recogido en la Ley del Suelo de 1956 en su artículo 60, proviene de las pautas culturales del organicismo, lo que para dicho autor supone una prolongación a lo social de la teoría de la evolución por selección natural de Darwin ${ }^{2}$, siendo esta doctrina sociológica y urbanística la que predomina en el momento de la redacción de la LS 56, en todo caso, sea cual sea el criterio cultural que justifica la aparición de estos artículos, la Ley del Suelo de 1956 apuntaba ya los problemas derivados de la aplicación de estas normas, que la legislación posterior acentuaría de forma clara, y que ponen de manifiesto la heterogénea y variada normativa que incidía sobre aquellos bienes que se pretendían proteger y en particular sobre la conservación del paisaje ${ }^{3}$.

Posteriormente la Ley de 1975 da nueva redacción al artículo 60 de la Ley de 1956 e introduce igualmente la limitación correspondiente a la densidad máxima en suelo urbanizable.

El texto refundido derivado de esta normativa fue aprobado como es bien sabido mediante RD 1346/1976, de 9 de abril, regulando las normas de aplicación directa en sus artículos 72 a 75 dentro del Capitulo denominado «Normas de Ordenación complementarias y subsidiarias del Planeamiento», estos preceptos fueron posteriormente desarrollados por el Reglamento de Planeamiento en los artículos 98 a 100 e integrados dentro del Titulo II de las Normas Complementarias y Subsidiarias del Planeamiento, si bien configuraron un Capítulo independiente denominado «De las Normas de Aplicación Directa», lo que en una primera aproximación

\footnotetext{
${ }^{2}$ Enrique PoRTo ReY, «La ordenación urbana en pequeños municipios. Las normas legales de aplicación directa» en vol. Col dirigido por Enrique PoRTo ReY, Planeamiento y Gestión Urbanística en Pequeños municipios, Madrid, Edit. Colegio Oficial de Arquitectos de Madrid, $19872^{\mathrm{a}}$ ed., página 42.

${ }^{3}$ Sobre un aspecto específico de las Normas de Aplicación Directa, la tutela del paisaje, puede verse su aplicación en la Ley del Suelo del 56 y en particular sobre la aplicación de los Planes Especiales a Lorenzo MARTín-Retortillo BAQuer, «Problemas jurídicos de la tutela del paisaje», Revista de Administración Pública, nº 71, mayo-agosto 73, página 427.
} 
daba pie a entender aplicable un criterio restrictivo en cuanto a su ámbito que parecía dirigido exclusivamente a unas determinados planes como eran las Normas Subsidiarias y las Complementarias, pero no a la totalidad de actividad de planeamiento municipal.

No obstante, estas Normas pronto se despojaron de esa aparente limitación predicándose de ellas su inmediata y directa aplicación existiese o no Plan urbanístico, por lo que se ha acusado al Reglamento de Planeamiento de incurrir en exceso de regulación con respecto al Texto Refundido de 1976 y en suma de alterar el carácter de estas Normas, las cuales pasan de ser normas reguladoras de una concreta obligación del planeamiento, es decir, de establecer la obligación de recoger entre sus determinaciones las de protección del paisaje y del entorno establecidos, entre otros, a los artículos 18, 27,2 o 36 c) 2 del mismo Reglamento de Planeamiento, tal como las había configurado el Texto de 1976, lo que supone atribuir al planeamiento el carácter de norma fundamental para la aplicación de los criterios de protección, a predicar el carácter preceptivo de aplicación directa que no venía reflejado en la norma a desarrollar ${ }^{4}$ existiese o no existiese Plan, lo que indudablemente introduce el problema del predominio de dichas normas sobre los contenidos recogidos en el planeamiento vigente.

La jurisprudencia no siguió el criterio de interpretación restrictiva que pudiera predicarse de estas Normas de Aplicación Directa y no se planteó en ningún caso el posible exceso del Reglamento de Planeamiento sobre el Texto Refundido de 1976, por lo que desde muy tempranamente postulo el carácter de norma de aplicación directa del artículo 73, siendo prueba de ello la STS de 30/06/82 (Aranzadi 1982\5246).

En el mismo sentido la jurisprudencia ha recogido no sólo el aspecto relativo a la aplicación de la Norma de forma directa sino también el carácter limitador de la potestad de planeamiento por cuanto como señala la STS de 24 de octubre de 1995 (Aranzadi RJ 1995\7708).

Cierto es que el artículo 73 invocado, desarrollado en el artículo 98 del Reglamento de Planeamiento (RCL 1978\1965 y ApNDL 13921), constituye una norma de aplicación directa, tanto en defecto de planeamiento como sobre éste, y sin perjuicio de que el planeamiento, sobre todo si es especial, pueda dedicar su atención a la salvaguarda de los valores a que

\footnotetext{
${ }^{4}$ Enrique SÁNChez GoYANES, «Urbanismo y protección del paisaje. Las (mal) llamadas y (peor entendidas ) normas de aplicación directa. Anulación por el TSJ de Cantabria de licencia para 17 viviendas junto a la Costa de Liendres», en Revista de Estudios Locales, nº 33, nov.-dic. 1999, página 96.
} 
se refieren los precitados artículos 73 y 98, caso en que las reglas de éstos despliegan una doble eficacia, de un lado, limitando la potestad planificadora y, de otro, operando como medida de la legitimidad de las determinaciones del Plan -Sentencia de 16 mayo 1995 (RJ 1995\3803) 5.

En consecuencia y desde la regulación contenida en el Texto Refundido de 1976, junto con el Reglamento de Planeamiento, se pueden establecer como normas de aplicación directa las que regulan los siguientes apartados:

- Construcciones en lugares próximos a carreteras.

- Adaptación al ambiente de las construcciones.

- Fijación de alturas en ausencia de Plan o Norma.

- Densidad máxima a fijar por los Planes Parciales.

Ciertamente, y tal como se recogía en la exposición de motivos de la Ley de 1975, nos encontramos, en los dos últimos casos, más bien con estándares urbanísticos que con Normas de Aplicación Directa y en este sentido la última de ellas, la relativa a la densidad máxima a fijar por los Planes Parciales, puede estimarse fuera del concepto de las Normas de Aplicación Directa en base a la exigencia de la existencia de una previa norma urbanística, el Plan Parcial, que impide su aplicación de forma inmediata y desde la Ley.

La situación descrita se ve en cierta medida alterada en su sistemática por el RD Leg 1/1992 de 26 de abril, pues este reduce el número de determinaciones que pueden considerarse como Normas de Aplicación Directa, recogiendo éstas en los artículos 138 y 139, preceptos que ya no son incluidas dentro del ámbito de las Normas Subsidiarias o Complementarias, sino como título independiente y bajo la rúbrica de «De las Normas de Aplicación Directa», limitando éstas a dos conceptos exclusivamente, la adaptación al ambiente y las determinación de las alturas en caso de inexistencia de Plan y dejando las prescripciones relativas a las construcciones próximas a las carreteras para la legislación sectorial, por lo que desaparece su regulación de la Ley, aunque no así del Reglamento de Planeamiento, pues el mismo no se ve afectado en este apartado por el RD 304/1993, de 26 de febrero, mientras que la densidad máxima se regula ahora en el artículo 83 del Texto Refundido del 92, dentro de las determinaciones que deben contener los Planes Parciales y en consecuencia en la sección relativa a los Planes de Desarrollo.

\footnotetext{
${ }^{5}$ En este mismo sentido la Sentencia del Tribunal Supremo de 21 de noviembre de 2000 (BDB TS 39802/2000)
} 
Procede por tanto analizar el artículo 138 como antecedente más inmediato de la protección del paisaje en la LOTRUSC.

\subsection{El artículo 138 a) del RD Leg $1 / 92$ de 26 de junio}

El artículo 138 del RD Leg 1/1992, de 26 de junio, contemplaba dos conceptos, separados en sus apartados a) y b).

El primer apartado, de carácter supletorio con respecto a la legislación urbanística que pudiesen dictar las Comunidades Autónomas, establecía la obligación de que las construcciones que se encontrasen en lugares inmediatos, o que formasen parte de un grupo de edificios de carácter histórico, arqueológico, típico o tradicional tendrían que armonizar con el mismo, señalando que, aun en el caso de que no existiese tal conjunto de edificios, si existiese alguno de gran importancia o calidad de los caracteres indicados debería efectuarse tal armonización.

Desde una perspectiva competencial, nos encontramos ante una norma que no es aplicación de las obligaciones que en orden al mantenimiento y conservación del Patrimonio Histórico-Artístico se recoge en la Ley 16/1985, de 25 de junio, del Patrimonio Histórico Español, pues el artículo 20 de dicha norma establece claramente las obligaciones que conlleva la declaración de un bien inmueble como Conjunto Histórico, Sitio Histórico o Zona Arqueológica como Bien de Interés Cultural, y este mismo principio puede encontrarse en las distintas normas autonómicas en relación con las categorías de bienes inmuebles recogidos en las mismas.

Ciertamente, si el fin de este apartado fuese recordar en la Ley del Suelo las obligaciones derivadas del cumplimiento de las normas protectoras del Patrimonio Cultural podría decirse que no habría hecho falta tales alforjas para ese viaje, pues el carácter preferente de esta normativa sectorial, recogida al artículo 20.1 de la Ley 16/85, hace innecesario su recordatorio en la normativa urbanística ${ }^{6}$, por lo que el precepto analizado debe actuar necesariamente de forma independiente a las declaraciones de la legislación del patrimonio histórico ${ }^{7}$ ya que en caso contrario duplicaría la declaración contenida al artículo 21 del propio RD Leg 1/92.

\footnotetext{
${ }^{6}$ En este mismo sentido Eduardo García de Enterría y Luciano Parejo Alfonso, Lecciones de Derecho Urbanístico, Madrid 1981, página 229.

${ }^{7}$ Maria del Pilar Bensusan Martín, La protección urbanística de los bienes inmuebles históricos, Granada Editorial Comares, 1996, página 94.
} 
Por tanto, ha de plantearse cuál es la finalidad del precepto, así para GoNZÁLEZ Pérez la necesidad de la norma deriva de, ante la pasividad de la Administración, consagrar en normas de rango de Ley estos «elementales preceptos» que permitan acudir a los tribunales como guardianes de la justicia y la ley, indicando que «preceptos tan claros y terminantes como el contenido en este artículo 138 harían innecesarias buen número de Planes y de controles» ${ }^{8}$.

No obstante, su aparente claridad no es tal, Tomas Ramón FernánDEZ ya señalaba en relación con el artículo 72 del Texto de 1976 que «las dificultades que ofrece la aplicación de esta norma son evidentes, ya que esta plagada de conceptos jurídicos indeterminados, pero, como es lógico, ello no significa nada en contra de su obligado respeto, incluso para los propios planes, cuyas determinaciones tiene que ajustarse necesariamente a ella» ${ }^{9}$.

Enrique PoRTo Rey ha señalado acertadamente que la norma trata de evitar la realización de modelos ideales aplicables indistinta, indiscriminada e indiferenciadamente a cualquier lugar o circunstancia, con lo que se pretende potenciar los valores inmanentes y permanentes, pues, según este autor, «si se permitiese la utilización de tipos característicos de una construcción estandarizada y masificada, serían señales inequívocas de que las fuentes de la creación se estarían agotando, de que la auténtica originalidad es suplantada por una constante tendencia a la copia, a la repetición mecánica e indiscriminada, a la uniformidad inerte, en la que corre peligro de desaparecer todo lo que represente en cada núcleo urbano su ambiente, signo de individualidad, de conciencia íntima, de fisonomía personal» ${ }^{10}$.

De lo indicado podemos concluir que el legislador conociendo que la existencia de determinadas circunstancias que singularizan unos concretos núcleos urbanos no pueden impedir o limitar su crecimiento, ni la sustitución necesaria de parte de sus inmuebles, pero exige para ello la salvaguarda de la imagen urbana que se ha ido generando mediante su proceso histórico de construcción, en consecuencia ha considerado oportuno establecer desde la Ley criterios de protección que permitan amparar este pai-

\footnotetext{
8 Jesús González Pérez, Comentarios a la Ley del Suelo (Texto Refundido de 1992), Madrid Edi-

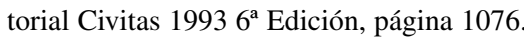

9 Tomás Ramón Fernández, Manual de Derecho Urbanístico. Madrid, Publicaciones Abella, 1986 $6^{\circ}$ edición, página 51.

${ }^{10}$ Enrique Porto Rey, La ordenación urbana en pequeños municipios. Las normas legales de aplicación directa, cit., pág. 43.
} 
saje urbano singularmente protegible. Ahora bien, dada la heterogeneidad de las circunstancias que concurren no ha prefijado de forma definitiva el supuesto de hecho, es decir, el criterio en virtud del cual el conjunto urbano o el edificio singular se hace digno de protección, que en todo caso no es una creación de la norma sino que dicho carácter puede predicarse del conjunto urbano exista o no el artículo estudiado, ni tampoco los parámetros en los que estos se efectúan debiendo en consecuencia remitir a un concepto amplio como es el de «armonizar» lo nuevo con lo existente, armonización que exige indudablemente la concurrencia de determinados parámetros, como es el uso de los materiales y colores usuales en el ámbito en el que se encuentra la nueva construcción, pero que requiere además un plus de garantía derivada del uso de las formas, de la distribución de los huecos, etc., cuyo establecimiento no corresponde al Derecho, por lo que debemos remitir, para su especificación, a disciplinas ajenas a este.

Sin perjuicio de su finalidad, la interpretación y aplicación de esta Norma, al igual que el resto de las incluidas en este Capitulo del Texto Refundido, han dado lugar a múltiples problemas en su aplicación, pues cualquier lector atento puede apreciar en la misma el conjunto de indeterminaciones que el mismo contiene, tales como «lugares inmediatos», «armonizar» o incluso la propia existencia de un edificio «de gran importancia o calidad de los caracteres indicados» que sin embargo no deben considerarse incluidos dentro de los de objeto de protección por la norma del Patrimonio Cultural.

La jurisprudencia ha venido haciendo frente a los problemas que plantea el artículo 138 a) procurando dar una respuesta especifica al mismo y así la Sentencia del Tribunal Superior de Justicia de Cantabria de fecha 23 de mayo de 2000 (BDB TSJ Cantabria 19392\2000) ha señalado que:

El art. 138 de la Ley del Suelo, por su vocación general, establece determinados principios protectores plasmados en verdaderos conceptos jurídicos indeterminados, necesitados de la indagación de la única solución justa posible, reservando el último control de su determinación, en cuanto al acotamiento de su ámbito de certeza, a los Tribunales de Justicia.

Por tanto y en lo que afecta al análisis de la búsqueda de esta única solución justa, o si de hecho existe capacidad en la Administración para la aplicación de una zona de decisión propia, así como su relación con la potestad de planeamiento podemos adelantar su destacado carácter de norma de aplicación directa y su prevalencia sobre el Plan, por lo que la STSJ de Cantabria anteriormente citada destaca que si se advirtiera discrepancia del plan o norma con el precepto legal, la prevalencia de este último obligará, para superar la contradicción o discrepancia, a modificar las deter- 
minaciones de aquél, para evitar actuaciones administrativas singulares, como el otorgamiento o la denegación de una licencia, en aplicación de un plan o norma que no tenga en cuenta o contradiga las determinaciones del artículo 138 TRLS o, a la inversa, en aplicación directa de éste no obstante existir un planeamiento urbanístico municipal formalmente aprobado. En cualquier caso, dice la Sentencia, la discrepancia debe ser superada, lógicamente, con la modificación del plan, no sólo por razones de legalidad y seguridad jurídica, sino también para evitar acciones contradictorias con los bienes jurídicos que el art. 138 trata de proteger ${ }^{11}$.

Ahora bien, esto no supone en ningún caso que tal preeminencia pudiera dar lugar a la aplicación de la Norma de Aplicación Directa contra el Plan y en este sentido ya lo recordó en su momento la STS de 7 de marzo de 1988 (Aranzadi RD 1988\1786) ${ }^{12}$ por lo que podemos concluir que caso de que la Administración apreciara la existencia de una discrepancia entre el Planeamiento y las Normas de Aplicación Directa la técnica adecuada pasaría no por la prevalencia de estas o de aquel sino por su congruencia, por lo que sería necesario proceder a la tramitación de la oportuna modificación del planeamiento con destino a recoger en el mismo estos principios con suspensión de las licencias durante los periodos permitidos por las normas urbanísticas aplicables.

Por su carácter de norma urbanística, no derivada de la de Patrimonio Cultural, el RD Leg 1/1992, de 26 de noviembre, atribuyó a la misma el carácter de norma supletoria con respecto a las que las CC.AA. deberían

${ }^{11}$ En este mismo sentido la STSJ de Cantabria de 14 de Septiembre de 1998 (Aranzadi RJCA 199813949)

${ }^{12}$ La STS de 7 de marzo de 1988 (Aranzadi RD 198811786) ante el acuerdo de un Ayuntamiento de aplicar criterios derivados de las Normas de Aplicación Directa en contra de las prescripciones recogidas en el Planeamiento ha señalado que:

Es indudable que este Acuerdo del Pleno del Ayuntamiento no era ni es legalmente idóneo para variar las condiciones de edificación establecidas en el Plan General Municipal definitivamente aprobado en su día mediante Resolución Ministerial; por lo que si el Plan autoriza a construir aquí un ático, es clara la ineficacia del mencionado Acuerdo para disponer lo contrario, pues no puede un simple Acuerdo Municipal derogar ni modificar el Plan General en las ocho grandes áreas que el indicado Acuerdo delimita en el centro urbano de La Coruña por la vía del artículo 73 de la Ley del Suelo, pues esto requeriría la tramitación de un expediente de modificación del Plan o una revisión general del mismo, ya que no se puede modificar un Plan pretendiendo aplicar generalizadamente en grandes áreas, en contra de sus dictados, normas de aplicación directa, como ya declaramos para casos análogos en nuestras Sentencias de 10 de junio de 1970 (RJ 1970\3101), 3 de mayo de 1971 (RJ 197122341), 27 de febrero de 1976 (RJ 19761481) y 9 de mayo de 1986 (RJ 19803061); por lo que se echa de ver la ineficacia manifiesta del expresado Acuerdo para impedir construir el expresado ático; y sin que tampoco puedan aplicarse, en contra de las disposiciones del Plan, las reglas del art. 99.2 del Reglamento de Planeamiento ya que su aplicación exige que no haya Plan (art. 74 de la Ley del Suelo), y aquí sí lo hay. 
dictar en el ejercicio de la competencia urbanística atribuida por la Constitución, en lógica consecuencia el presente apartado del artículo 138, dado su carácter supletorio, fue declarado inconstitucional en la S.T.C 61/1997, de 20 de marzo, recaída sobre la Ley 8/1990 y el Texto Refundido de 1992.

\subsection{El artículo 138 b) del RD Leg $1 / 92$ de 26 de junio}

El apartado b) del artículo 138 pese a su aparente relación con la protección del Patrimonio Cultural no se encuentra tampoco ligado a dicho concepto.

A tal efecto dicho artículo establece que:

En los lugares de paisaje abierto y natural, sea rural o marítimo, o en las perspectivas que ofrezcan los conjuntos urbanos de características histórico-artísticas, típicos o tradicionales, y en las inmediaciones de las carreteras y caminos de trayecto pintoresco, no se permitirá que la situación, masa, altura de los edificios, muros y cierres, o la instalación de otros elementos, limite el campo visual para contemplar las bellezas naturales, rompa la armonía del paisaje o desfigure la perspectiva propia del mismo.

Para el Tribunal Constitucional esta norma debe entenderse incluida dentro de la competencia del artículo 149.1.23 de la Constitución, es decir, la relativa a la conservación del medio ambiente y así afirma en la sentencia 61/1997, de 20 de marzo, que:

El art. 138, b) se basa en el art. 149.1.23 CE. La STC 149/1991, fundamento jurídico 1, D), afirma que el art. 149.1 .23 permite al Estado establecer «toda la normativa que considere indispensable para la protección del medio ambiente». La protección de los valores estéticos del paisaje es también protección del medio ambiente.

Obvio es por tanto que la protección otorgada en este apartado es al paisaje como tal y no el monumento o al Conjunto Histórico para cuya protección ha de acudirse a la normativa sectorial, esto conlleva indudablemente una carga de subjetividad extraordinaria pese a que algunos autores hayan intentado preconizar de este un carácter objetivo ${ }^{13}$, prueba de ello es la Sentencia del Tribunal Constitucional 102/1995, de 26 de junio, reca-

\footnotetext{
${ }^{13}$ Para una análisis de la aplicación concreta del artículo 138, b) del RD Leg 1/92 de 26 de Noviembre puede consultarse Enrique SÁNCHEZ GoyANES, «Urbanismo y protección del paisaje. Las (mal) llamadas y (peor entendidas ) normas de aplicación directa. Anulación por el TSJ de Cantabria de licencia para 17 viviendas junto a la Costa de Liencres», en Revista de Estudios Locales, n 33, nov.-dic. 1999, páginas 78 y ss.
} 
ída en los recursos de inconstitucional interpuesto por diversas CC.AA. contra la Ley 4/1989, de 27 de marzo, de Conservación de los Espacios Naturales y de la Flora y Fauna Silvestre, que manifiesta de forma rotunda que:

Por otra parte, ligado a todo lo ya inventariado está el paisaje, noción estética, cuyos ingredientes son naturales - la tierra, la campiña, el valle, la sierra el mary culturales, históricos, con una referencia visual, el panorama o la vista, que a finales del pasado siglo obtiene la consideración de recurso, apreciado antes como tal por las aristocracias, generalizado hoy como bien colectivo, democratizado en suma y que, por ello, ha de incorporarse al concepto constitucional del medio ambiente como reflejan muchos de los Estatutos de Autonomía que luego se dirán.

Por tanto, para el Tribunal Constitucional dentro del concepto de medio ambiente:

ya desde su aparición en nuestro ordenamiento jurídico el año 1916, sin saberlo, se incorporan otros elementos que no son naturaleza sino Historia, los monumentos, así como el paisaje, que no es sólo una realidad objetiva sino un modo de mirar, distinto en cada época y cada cultura.

Si obviamente no nos encontramos ante una realidad objetiva, pues esta depende del mirar distinto en cada época y cultura, difícilmente pueda atribuirse a esta Norma de Aplicación Directa un criterio de aplicación indubitado para cada ocasión, lo que obviamente genera un semillero constante de inseguridad en la aplicación de la misma, si bien se ha afirmado que «Sin embargo, las mayores dificultades encontradas en la valoración estética de los paisajes son las mismas que las existentes para cualquier otra valoración estética, como puede ser la de obras de arte» ${ }^{14}$.

Esta declaración debería hacernos plantear si nos encontramos ante conceptos exclusivamente técnicos o científicos, entendiendo por tal aquellos para cuyo conocimiento es preciso disponer de conocimientos que pertenecen a ámbitos especializados del saber, y para cuya aplicación la Administración dispondría de una determinada discrecionalidad técnica, así, algún autor ha incluido la apreciación del paisaje dentro de este campo de la discrecionalidad ${ }^{15}$, sin perjuicio de lo cual no podemos afirmar la existencia de un área del conocimiento que fije exclusivamente los pará-

\footnotetext{
${ }^{14}$ Carlos Martínez Caro y Alfonso Vergara Gómez, «Paisaje natural y calidad de las implantaciones turísticas», Revista de Derecho Urbanístico, n 92 , marzo-abril 1985, edición electrónica, conteniendo el mismo un interesante estudio sobre metodología para la evaluación del paisaje.

${ }^{15}$ Así Marzuoli citado por Eva Desdentado Daroca, Los problemas técnicos del control judicial de la discrecionalidad técnica, un estudio crítico de la Jurisprudencia, Madrid, Ed. Civitas, 1997, página 53.
} 
metros científicos que determinen la protección del paisaje pues este pertenece a un ámbito como es el de la estética ${ }^{16}$ dado a la concurrencia de múltiples variables y a la existencia de un elemento emocional no exclusivo de la ciencia, lo que no implica que para su determinación no puedan ser aplicados determinados criterios artísticos o estéticos que formen parte de una determinada rama del saber ${ }^{17}$ pero que no pueden considerarse exclusivos de ese arte, lo que no impide obviamente que para la determinación de la valoración deban desecharse las apreciaciones meramentes subjetivas.

Ahora bien la limitación derivada de la protección del paisaje no supone una interdicción a situar en dichas áreas edificaciones, sino mas bien a impedir que la masa y altura de la construcción en dicha zona no rompa la armonía del paisaje ni desfigure la perspectiva propia del mismo ${ }^{18}$, por lo que en todo caso el problema se reduce a la verificación del cumplimiento de estos requisitos, para lo cual es necesario, conforme señala la STS de 26 de septiembre de 1975, que «se establezca clara y precisamente cuál es el paisaje, cómo se quiere proteger, que se habilite normativamente al Ayuntamiento para denegar por tal causa la licencia, que se determinen los límites referentes al uso del suelo, destino, volumen y estética de las construcciones y que finalmente se acredite adecuadamente que el edificio, caso de ser construido, lesionará aquel paisaje» ${ }^{19}$.

Aquí vuelve a plantearse el problema relativo a la indeterminación de los conceptos utilizados, y al igual que en el apartado a) del mismo artículo se ha de señalar que la jurisprudencia en Sentencias de la sala Tercera del Tribunal Supremo de 21 de noviembre de 2000, o 16 de junio de 1993, ha señalado que la no rotura de la armonía del paisaje o la desfiguración de las perspectivas propias del mismo, encierran conceptos jurídicos indeterminados, pero de indudable naturaleza reglada, aunque en su apreciación se introduzca con frecuencia un porcentaje de discrecionali-

\footnotetext{
${ }^{16}$ Ciertamente en este punto el análisis de los conceptos sobre la estética dominante en cada época nos lleva a limitar el campo de incertidumbre que se nos plantea, en este sentido puede verse Santiago GonZÁlez-VAras IbáÑez, La Rehabilitación Urbanística, Pamplona, Aranzadi 1998, página 230.

${ }^{17}$ En todo caso para algunos autores puede encuadrarse los problemas derivados de la discrecionalidad técnica dentro del campo de los conceptos jurídicos indeterminados, en este sentido Eva DesDentado Daroca, Los problemas técnicos del control cit página 43

${ }^{18}$ STSJ de Cataluña de 15/05/00 ( BDB TSJ Cataluña 1806612000)

${ }^{19}$ Arturo GonZÁLEZ QuinZA, «La protección del paisaje frente a las agresiones producidas por la instalación del servicio publico telefónico», en Revista de Derecho Urbanístico, nº 98 mayo-junio 1986, edición electrónica.
} 
dad, en razón del halo de dificultad que caracteriza el espacio de incertidumbre que media entre las zonas de certeza positiva y negativa (sentencias del T.S. de 31 de diciembre 1988, 8 de noviembre de 1990 y 12 de abril de 1996) ${ }^{20}$.

La sentencia citada apunta de hecho el problema, no sólo terminológico sino de concepto, que plantean a la jurisprudencia las Normas de Aplicación Directa en cuanto a su carácter regulador de potestades regladas o discrecionalidad y, en su caso, de la aplicación a las mismas de la técnica de los conceptos jurídicos indeterminados y de la existencia de un halo de incertidumbre en éstos que rompen el principio de existencia de una única solución justa, planteando los problemas de quién puede determinar tales conceptos como «armonía», etc., lo que obviamente nos llevan al concepto de control de las apreciaciones técnicas, entendidas éstas como la actividad de búsqueda de respuestas a problemas prácticos mediante la utilización de criterios técnicos, que pueden ser no solo de la ciencia pura sino también de las sociales y las artes ${ }^{21}$, cuestiones todas ellas que analizaremos en los apartados siguientes.

\section{FINALIDAD DE LAS NORMAS DE APLICACIÓN DIRECTA}

La primera cuestión que es necesario plantear en relación a las Normas de Aplicación Directa es cuál es la finalidad que nuestro ordenamiento jurídico atribuye a las mismas dentro del ámbito del Derecho urbanístico y concretar quien es el sujeto al que van dirigidas.

En una primera aproximación puede afirmarse que, ya desde la Ley de 1956, estas Normas se han configurado como principios que han de regir en la ordenación de un territorio en ausencia de planeamiento, así, se ha señalado que las mismas son mecanismos, ciertamente mas modesto e imperfectos que el planeamiento, a través de los cuales puede producirse una cierta ordenación en ausencia del planificador, apelando para ello no solo a las normas recogidas en la Ley del Suelo sino a las de carácter sectorial, tales como las de carreteras, costas, aguas, etc. ${ }^{22}$, lo que de hecho

\footnotetext{
${ }^{20}$ STSJ de Madrid de 15/01/02 (BDB TSJ Madrid 11225/2002).

${ }^{21}$ Eva Desdentado Daroca, Discrecionalidad Administrativa y Planeamiento Urbanístico Navarra, Ed Aranzadi, 1999, 2ª ed., página 137.

22 Ricardo Santos Díez y Julio Castelao Rodríguez, Derecho Urbanístico, Manual para juristas y técnicos, Madrid, Ed. El Consultor de los Ayuntamientos, 1999, página 179.
} 
permitiría ejercer directamente los derechos edificatorios reconocidos en la Ley por los propietarios aun en ausencia de Plan, pues en tales casos las Normas contienen la mínima regulación necesaria para la concesión de las licencias urbanísticas por parte de la Administración responsable, función que ha de estimarse lógica en tanto en cuanto surge en la Ley de 1956, ampliada en la de 1975, que se enfrenta ante una situación de hecho en la que lo general era la ausencia de planeamiento, lo que necesariamente requería el establecimiento desde la Ley de las prescripciones que impidiesen la paralización o suspensión de las autorizaciones de construcción pero a la vez que impidiesen los atentados mas flagrantes contra determinados valores dignos de protección.

Con este mismo criterio se ha interpretado por la jurisprudencia cuando ha señalado, como lo efectúa en la STS de 7 de marzo de 2002 (Aranzadi RJ 2002\2671), que:

Dado que (según lo que se deduce del pleito) con anterioridad al año 1988 el Municipio de Potes no tenía normas urbanísticas propias, la licencia en cuestión sólo estaba sometida al Derecho urbanístico propio de los Municipios sin Plan ni Normas Subsidiarias, a saber, las normas de directa aplicación contenidas en los artículos 73 y 74 del Texto Refundido de la Ley del Suelo de 9 de abril de 1976

No obstante, no es esta función de suplir al planeamiento la única de posible atribución a las Normas de Aplicación Directa, dentro de las mismas podemos entrever dos clases de prescripciones en función de su carácter directo o supletorio, es decir por una parte aquellas que son aplicables con carácter directo y prevalecen sobre la ordenación recogida en el Plan ${ }^{23}$ y aquellas que, como hemos señalado, tienen un mero carácter de derecho supletorio en defecto de Plan y que permitirían a los propietarios el desarrollo de sus derechos urbanísticos directamente desde la Ley sin necesidad de intermediación del planificador ${ }^{24}$.

En consecuencia, bajo una misma denominación nos encontramos con dos realidades bien distintas, por una parte, normas de carácter necesario que se superponen al Planeamiento, cualquiera que éste sea, y que permiten la impugnación de concretos actos conformes al Plan pero contrarios a

\footnotetext{
${ }^{23}$ Así la STS de 18 de abril de 2000 (Aranzadi 200044943) viene a señalar que:

Sin embargo, el artículo 73 TRLS constituye una norma de aplicación directa, que puede ser invocada como razón inmediata de la nulidad de una licencia, con independencia de su formal adecuación a las determinaciones contenidas en el planeamiento, por lo que no cabe oponer éste para excluir la observancia de sus prescripciones
}

${ }^{24}$ Situación que puede predicarse del antiguo artículo 74 del TRLS de 1976. 
dichas normas y, por otra parte, auténtico Derecho supletorio que solo tiene vigente en defecto de previsión del planificador.

Debe recordarse por tanto aquí que dentro de las posibles clasificaciones que pueden efectuarse de las normas, pueden las mismas dividirse en normas necesarias o supletorias ${ }^{25}$, las primeras se establecen para el supuesto de que se trate de una regulación forzosa, mientras que las segundas solo son aplicables en caso de falta de regulación por el interesado.

Como señala Albaladejo, «lo expuesto no contradice el carácter imperativo que antes se afirmó de toda norma. Lo que pasa es que el término imperativo se utiliza en dos sentidos; y las normas supletorias, que no son imperativas en el sentido que ahora contrapongo normas necesarias (o imperativas ) a normas supletorias sí son imperativas en el sentido de que siempre obligan a lo que mandan, bien que solo mandan para el caso de que los interesados no hayan regulado el punto diversamente, razón por la que no se aplican sino en este caso (porque no están dictadas sino por él)».

Esta supletoriedad puede establecerse no sólo de la autorregulación que los particulares puedan establecer de sus relaciones jurídicas, como ocurre en el campo de Derecho civil, sino que ésta puede venir referida a la regulación expresa realizada por otro ente o norma de rango inferior, por lo que su vigencia y aplicación depende de que dentro del ámbito o sector normativa en que nos movamos encontremos una regulación expresa a la que se remite la norma de reenvio.

Ciertamente en el ámbito del Derecho administrativo debemos actuar con criterios propios por lo que no es extrapolable de forma mecánica las técnicas acuñadas en el Derecho civil en cuanto al carácter necesario o supletorio de una norma, pues las características especiales del elemento subjetivo al que se dirige la misma y el cumplimiento de los fines de interés general exigibles en toda actuación de la Administración no permiten, en todo caso, atribuir a estas un ámbito de libertad configurador de sus relaciones jurídicas, tal como para el caso de la contratación ha recogido la STS de 25 de julio de 1989 (Aranzadi RJ 1989\6114) ${ }^{26}$.

\footnotetext{
${ }^{25}$ Manuel Albaladejo, Derecho Civil.-I.-Introducción y parte general, Barcelona, Librería Bosch, 1983 , página 30

${ }^{26}$ Esta sentencia viene a indicar que : Así pues, como regla general las normas sobre el contenido de los contratos administrativos son de derecho necesario y no contractual, a diferencia de lo que ocurre en la contratación civil en que en regla es exactamente la contraria., siendo la razón de esta diferencia, a juicio del Tribunal Supremo: el que esta subordinación de la autonomía de la voluntad a lo normativo que tiene lugar en la contratación administrativa tiene su razón de ser en la nece-
} 
No obstante, si bien es cierto que la interpretación del carácter de una norma como de Derecho necesario o supletorio en el ámbito del Derecho administrativo goza de características peculiares, dado el sujeto a las que las mismas se dirigen, no lo es menos que en multitud de ocasiones el propio ordenamiento jurídico nos remite a una norma de rango inferior para completar la regulación de la situación de hecho inicialmente predeterminada, previendo en su caso una regla de aplicación subsidiaria en caso de inexistencia de esta normativa reguladora.

En consecuencia y dado el carácter predicable de las Normas y su función se puede decir que los sujetos a quienes van dirigidas son:

a. El planificador, pues ésta debe observar en las determinaciones recogidas en el Planeamiento aquellas prescripciones que se imponen al mismo de forma necesaria, de tal manera que no sólo ve limitada su capacidad de actuar sobre el entorno físico por la necesidad de cumplir las obligaciones de resultado establecidas en las Normas, sino que debe concretar en el planeamiento aquellos elementos que permitan superar los elementos de indeterminación que se contienen en las Normas para lograr con la aplicación del planeamiento la obtención de auténticos actos reglados, todo ello sin perjuicio de que éstas pueden ser, igualmente, objeto de aplicación de forma casuística en los casos de ausencia de planeamiento.

b. El propietario de los terrenos en cuanto los derechos patrimoniales de su propiedad deben ejercerse, en ausencia de Plan, de acuerdo con la prescripciones que de forma directa se contienen en la Ley del Suelo, sirviendo las mismas como «plan de mínimos» para la patrimonialización de sus derechos urbanísticos y configurando desde la Ley del Suelo el estatuto básico de la propiedad afectada de acuerdo con la función social predicable de la misma.

\section{APLICACIÓN DE LA NORMA, DISCRECIONALIDAD Y CONCEPTO JURÍDICO INDETERMINADO}

La diferente función que se ha señalado de las Normas de Aplicación Directa exige analizar qué efectos producen sobre el sujeto que la aplica, así como para el que se destinan y qué facultades u obligaciones, para el primero de ellos, conlleva su determinación y aplicación al caso concreto.

sidad de proteger tanto los intereses de la Administración (normas sobre mora, fianzas, interpretación y modificación de los contratos, etc.), como los del contratista (normas sobre riesgo y ventura, revisión de precios, etc.). 
A tal efecto debemos distinguir, como se ha indicado, las dos funciones fundamentales que cumplen las Normas de Aplicación Directa, es decir, la de servir de aplicación inmediata de la Ley en ausencia de planeamiento y la de establecer un conjunto de reglas sobre las que el planificador debe desarrollar su potestad de ordenar el espacio, la diferencia señalada es necesaria por cuanto en el primer caso nos encontramos con un acto administrativo de aplicación directa de la Ley, mientras que en el segundo se genera una norma de carácter general configuradora de futuras relaciones jurídicas, que si bien se encuentra subordinada a la Ley innova el ordenamiento.

\subsection{Las normas de aplicación directa como ordenación inmediata de la Ley}

Obvio es que el problema de la aplicación de cualquier norma deriva, por una parte, de la mejor o peor sintaxis de la misma y de su adecuada estructura normativa, pero también necesariamente de la semántica de los conceptos que contiene y de su relación con el resto del ordenamiento jurídico, la combinación de todos estos elementos nos determinará la mayor o menor facilidad aplicativa del contenido de la norma por parte del operador jurídico.

Cuando una norma contiene en sí todos los elementos que permiten su aplicación directamente por encontrarse los conceptos en ella contenidas perfectamente determinados, o ser estos inmediatamente determinables, sin necesidad de acudir a otras normas o conceptos situados fuera de la misma y además de la estructura de la norma se deriva una única consecuencia, no se plantea ningún problema aplicativo, si la norma establece «se concederá licencia de obra cuando la altura máxima de la edificación sea inferior a 13 metros, medidos desde el alero de la construcción a la rasante con la acera» es fácil colegir que la norma contiene en si los elementos suficientes para su aplicación, sin perjuicio de que los hechos sobre los que actúa tengan una mayor o menor complejidad.

Debe tenerse en cuenta, en todo caso, la estructura normativa sobre la que actuamos y de la que puede desprenderse que esa indeterminación de la que hablamos se encuadre bien en el supuesto de hecho habilitante de su aplicación, y por tanto en la posibilidad de aplicar la misma consecuencia jurídica para distintos hechos caracterizados por concurrir en ellos elementos adicionales que deben ser integrados en el supuesto de hecho junto a otros siempre presentes y prefijados en la norma, o bien a las consecuencias que la aplicación de la norma conlleve partiendo del supuesto 
de hecho determinado en base a las distintas reglas jurídicas aplicables a cada caso concreto.

Igualmente ha de plantearse cuál es la actuación que ante cada elemento de la estructura normativa permite nuestro ordenamiento jurídico, es decir, si ante esta indeterminación el aplicador de la norma se limita a desarrollar una función meramente «cognoscitiva» o de apreciación o bien tiene un ámbito de decisión propio que puede adoptar a la vista de los posibles hechos o consecuencias a integrar en la norma, es decir, una función «volitiva» ${ }^{27}$.

Ahora bien, podemos afirmar que partiendo de la existencia de una norma, dejando aparte las situación de creación de la misma, en realidad el ámbito de libertad sólo se encontraría en la fijación de los hechos determinantes de su aplicación y en la libertad concedida a la Administración de aplicar o no las consecuencias, pero en ningún caso en que ésta disponga de libertad para la adopción de una consecuencia u otra que no sea la derivada de la inclusión en la norma de una cláusula de «cópula» ${ }^{28}$, pues en tal caso ciertamente podríamos entender que más que un ámbito de libertad lo hay de discrecionalidad y la aplicación del Derecho exige siempre su carácter objetivo ${ }^{29}$.

Así como ocurre en el caso analizado de las Normas de Aplicación Directa es preciso su integración con otros conceptos ya sean jurídicos, técnicos o del lenguaje común, ya que en estas el supuesto de hecho habilitante de la aplicación de la norma no se encuentra completamente determinado o se encuentra inacabado, de ahí que la aplicación de las reglas semánticas necesarias para su concreción, o la aportación de los elementos precisos para completar el supuesto de hecho, precisen de actuaciones adicionales que permitan concretar los elementos que dan lugar a una solución exclusiva de la misma para un caso concreto, ciertamente aquí no se trata de una aplicación supletoria del Derecho por cuanto la norma controvertida no es aplicable sólo en defecto de otra norma, tampoco nos encontramos con una norma en blanco, entendiendo por tal la que requiere para su interpretación y aplicación de otra norma situada ad extra de la misma y no se trata de problemas derivados de la interpretación de la

\footnotetext{
${ }^{27}$ M. BaCigalupo, La discrecionalidad administrativa, cit., página 29.

${ }^{28}$ La afirmación de la existencia de un ámbito de libertad derivado de una cláusula de cópula en la estructura normativa debe ser no obstante matizada, pues no es infrecuente encontrar jurisprudencia en la que pese a la inclusión literal en la norma de la cláusula «podrá» ésta es interpretada como «deberá».
}

${ }^{29}$ M. Bacigalupo, La discrecionalidad administrativa, cit. Página 192. 
norma pues aquí lo que hace fundamentalmente el aplicador de ésta es perfeccionar o integrar el supuesto de hecho normativo ${ }^{30}$.

A la vista de todo ello, debemos plantearnos si en realidad, y en el caso de las Normas de Aplicación Directa, nos encontramos ante lo que la doctrina denomina conceptos jurídicos indeterminados o bien ante el otorgamiento a la Administración de un ámbito de discrecionalidad administrativa. En una primera aproximación, y con respecto al primero de los conceptos, se ha afirmado que nos encontraríamos con una técnica que emplean las leyes, ante la necesaria ambigüedad y generalidad del lenguaje, y a los que cuando las partes en un proceso discrepan sobre los mismos corresponde al juez determinar si el supuesto de hecho discutido se acomoda o no a este tipo de conceptos ${ }^{31}$.

En nuestro Derecho ha cobrado fuerza la teoría de que los conceptos jurídicos indeterminados, en cuanto técnica limitadora de la discrecionalidad administrativa, deben llevar exclusivamente a una única solución justa, es decir, a una solución que es la única acorde con la idea de justicia que la norma expresa ${ }^{32}$, lo que la hace distinguirse de la discrecionalidad administrativa ${ }^{33}$.

Así, la STS de 30/05/00 (Aranzadi RJ 2000\5114), viene a recoger estos principios y señala:

La sentencia recurrida viene a apoyar tal fallo estimatorio en que en las decisiones basadas en el principio de discrecionalidad ha de partirse del supuesto de la existencia de diversas soluciones alternativas jurídicamente indiferenciadas entre las que ha de efectuarse la elección, mientras que en los supuestos en los que la habilitación legal para seleccionar se confiere mediante el mandato de aplicación de un concepto jurídico indeterminado, cual es el de la "proposición más ventajosa», la decisión del órgano actuante requiere un proceso intelectivo en el que, atendiendo a la realidad de las circunstancias que se le muestran, y no a su libre juicio, ha de concluirse en cuál de las ofertas presentadas es subsumible en el único

\footnotetext{
${ }^{30}$ M. BACIGALUPO, La discrecionalidad administrativa (estructura normativa, control judicial y límites constitucionales de su atribución), Madrid, Editorial Marcial Pons, 1997, página 200.

${ }^{31}$ Eduardo García de EnTERRía, Democracia, Jueces y control de la Administración, Madrid, Ed Civitas, 1998, $4^{\text {a }}$ ed., páginas 134 y ss.

32 Eva Desdentado Daroca, Discrecionalidad Administrativa y Planeamiento Urbanístico, Navarra, Ed Aranzadi, 1999, 2ª ed. Página 114.

${ }^{33}$ No obstante, otros autores han señalado la necesidad de efectuar una cierta graduación en orden a la consideración de la existencia de una única solución justa en función de determinados tipos de conceptos jurídicos indeterminados para cuya concreción y aplicación es preciso llevar a cabo valoracionesde política admnistrativas que están atribuidas, por el ordenamiento jurídico a la Administración, así Eva Desdentado Daroca, Discrecionalidad Administrativa, ob. cit, página 133.
} 
supuesto de solución justa, que se corresponde con la necesidad de seleccionar entre aquéllas precisamente la única que pueda merecer la calificación de «proposición más ventajosa», lo que ha de verificarse de conformidad con los criterios establecidos en los pliegos de cláusulas administrativas particulares del concurso.

En lo que se refiere a la discrecionalidad administrativa de ésta se afirma que permite, ya veremos que nunca con arbitrariedad, elegir la solución que estime más adecuada o, como se ha señalado, esta permite la existencia de una «pluralidad de soluciones justas» ${ }^{34}$ y supone la libertad de la Administración para elegir una entre varias soluciones igualmente justas $-y$ por tanto indiferentes jurídicamente ${ }^{35}$ -

La no equiparación entre conceptos jurídicos indeterminados y discrecionalidad administrativa, tiene su reflejo en sus distintos efectos, en este sentido se ha afirmado que mientras en los actos discrecionales se entiende que los Tribunales deben limitarse a controlar la legalidad de la decisión, es decir, a practicar lo que se conoce como control negativo, sin poder entrar a valorar el fondo del asunto, cuando se aplican conceptos jurídicos indeterminados se entiende que el Tribunal es perfectamente capaz de aplicar el concepto (al igual que aplica los conceptos indeterminados que se emplean en normas de Derecho privado), sustituyendo, en su caso, la aplicación que hizo la Administración, todo ello con las únicas excepciones, interpretadas caso por caso y restrictivamente, de los supuestos en que se reconoce a la Administración un margen de apreciación $^{36}$.

Por tanto, si la aplicación del concepto jurídico indeterminado da lugar a una única solución es lógico concluir que, desde una perspectiva objetiva, cualquier persona ajena a la Administración debe poder alcanzar esa misma solución siempre que aplique los mismos principios generales que ha debido aplicar la Administración, lo que obviamente permite aventurar que los órganos jurisdiccionales pueden, en caso de no considerar conforme la decisión de la Administración, sustituir la misma pues existiendo una única solución posible no tiene por qué diferirse la misma a una posterior resolución de la Administración.

\footnotetext{
34 Tomás Ramón Fernández, De la arbitrariedad de la Administración, Madrid, Ed. Civitas 2002, página 105.

${ }^{35}$ STS de 28 de octubre de 1987 (Aranzadi RJ 1988\10203).

${ }^{36}$ Raul Bocanegra Sierra y Alejandro Huergo Lora, «Un paso atrás en el control judicial de la discrecionalidad: su confusión con los conceptos jurídicos indeterminados y la dispensa del deber de motiva», en Revista Española de Derecho Administrativo, No 111, página 31.
} 
No obstante, pese a la aparente uniformidad jurisprudencial, no son estos criterios pacíficos en nuestra doctrina, y así en lo que afecta al control de la discrecionalidad administrativa autores como Luciano PAREJO Alfonso la han refutado, en base a no considerar admisible la aplicación generalizada de lo que se ha denominado como las técnicas fundamentales de control de la discrecionalidad, pues, para este autor, ni el uso del criterio de aplicación de la realidad de los hechos es suficiente argumento, pues precisamente la finalidad de la actuación de la Administración puede ser la transformación y superación de está, ni el principio de interdicción de la arbitrariedad o el criterio de racionalidad son determinantes para configurar esa exclusiva y única solución dada su escasa concreción ${ }^{37}$, de lo que se deriva la existencia de una esfera de libertad en la Administración que permitiría a esta alcanzar una solución valida en Derecho pero no necesariamente igual en todas las ocasiones.

Igualmente con respecto a la discrecionalidad administrativa se ha señalado que lo que sí parece que puede afirmarse es precisamente la dificultad de definir la discrecionalidad administrativa como un único concepto, en este sentido se plantea el concepto de discrecionalidad administrativa como un supraconcepto, del que pueden identificarse otros conceptos como específicos de discrecionalidad, tales como la «discrecionalidad judicial», «discrecionalidad administrativa», etc., en suma, el supraconcepto de discrecionalidad haría referencia a un determinado modo de realizar algo en el que la decisión puede efectuarse dentro de un margen de apreciación dejado por el ordenamiento mediante la realización de una elección entre diferentes alternativas sobre la base de criterios extrajurí$\operatorname{dicos}{ }^{38}$.

Por otra parte, en cuanto a los conceptos jurídicos indeterminados la jurisprudencia igualmente ha señalado la dificultad de establecer para estos una única y exclusiva solución, pues en los mismos se ha de reconocer a la Administración un margen de apreciación en razón del halo de dificultad característico de los conceptos jurídicos indeterminados y que da lugar a la existencia de una zona de incertidumbre que media entre las zonas de certeza ${ }^{39}$, en los cuales resulta necesario, para rectificar la apreciación que de aquél haga la Administración, acreditar que ésta ha obrado

\footnotetext{
${ }^{37}$ Luciano Parejo Alfonso, Administrar y juzgar: dos funciones constitucionales distintas y complementarias, Madrid, Ed. Tecnos, 1993, página 36.

${ }^{38}$ Eva Desdentado Daroca, Discrecionalidad Administrativa y Planeamiento Urbanístico, ob. cit., páginas 70 y 71 .

${ }^{39}$ STS 28 de octubre de 1997 (Aranzadi RJ 1998\10203).
} 
con arbitrariedad o irrazonabilidad, si se trata de conceptos que implican la utilización de criterios valorativos, tales como los de «interés público» (STS de 25/05/98 Aranzadi RJ 1998\4486), o la «proposición más ventajosa o conveniente» (STS de 19/07/00 Aranzadi RJ 200017428).

En este sentido M. BACigaluPo afirma que la exigencia de una única solución justa para los conceptos jurídicos indeterminados parte de una premisa incorrecta, debiendo establecer la diferencia entre los conceptos determinados, en los que existe una única interpretación, e indeterminados, en los cuales se reconoce la existencia de un halo o zona de incertidumbre. Así, en los primeros, el concepto se expresa siempre mediante reglas semánticas que remiten a condiciones a la vez necesarias y suficientes, por lo que no se produce ninguna zona de vaguedad entre la zona suficiente y necesaria para su aplicación y la zona necesaria y suficiente para su inaplicación, mientras que los segundos no es posible expresarlos mediante reglas semánticas que remitan a condiciones a la vez suficientes y necesarios, sino sólo suficientes, por lo que la zona de incertidumbre se produce entre las zonas de condición suficiente para su aplicación y las zonas de condición suficiente para su inaplicación ${ }^{40}$.

En definitiva, se ha sostenido la imposibilidad de mantener una distinción y separación estricta entre conceptos jurídicos indeterminados y discrecionalidad, existiendo para algunos autores una equiparación entre conceptos jurídicos indeterminados y discrecionalidad administrativa ${ }^{41}$, afirmando Juan Igartua SalaVARRía que «Si por «discrecionalidad» cabe entender genéricamente posibilidad de elección, entonces en la disección de los actos discrecionales administrativos que se ha efectuado en la cita anterior, se detectan dos especies de discrecionalidad (que las designaré con nomenclatura aproximada): una interpretativa (cuando las disposiciones jurídicas vienen expresadas con lenguaje indeterminado) y otra estratégica (cuando -independientemente de si el lenguaje legal es indeterminado o no- las disposiciones jurídicas no prescriben - ni determinada ni indeterminada - cuál, de entre los medios conducentes a un fin,

\footnotetext{
${ }^{40}$ M. BacigaluPo, La discrecionalidad administrativa, cit., página 196.

${ }^{41}$ M. SÁnchez Morón, Discrecionalidad Administrativa y control judicial, Madrid, Ed. Tecnos, 1994, página 116 y 117, que ha señalado que:

«... por regla general, y no obstante la afirmación enfática de que la aplicación de estos conceptos permite un control jurisdiccional completo, se admite por la jurisprudencia que la «unicidad» de la solución justa es compatible con el respeto de un «margen de apreciación» a favor de la Administración para la concreción del concepto en cada caso. Pero si se admite que existe ese margen de apreciación, quiere decirse que la Administración puede llevar a cabo aplicaciones distintas del concepto que serían igualmente lícitas, lo que pone en cuestión que exista una sola solución jurídicamente aplicable.
} 
ha de adoptarse). En tosca simplificación: la primera estaría propiciada por cómo se dicen las cosas en la Ley y el Derecho; la segunda por las cosas que no se dicen

«La discrecionalidad «interpretativa» está representada formidablemente por los tan traídos «conceptos indeterminados». La discrecionalidad «estratégica» encuentra una óptima ejemplificación en las llamadas «normas teleológicas» ${ }^{42}$.

Por tanto, si en el caso de los conceptos jurídicos indeterminados la actuación de la Administración consiste en la fijación de un criterio de aplicación para cada uno de los conceptos indeterminados que permiten aplicarlos o inaplicarlos en sus respectivas zonas de incertidumbre, en el caso de la discrecionalidad la operación consiste en la fijación de aquellas condiciones adicionales cuya concurrencia, junto con el hecho normativo, suponen la adopción preceptiva de cada una de las consecuencias jurídicas determinadas en la norma, de lo que puede concluirse que conceptos jurídicos indeterminados y discrecionalidad no se diferenciarían cualitativamente ${ }^{43}$; otros autores matizan este criterio atribuyendo a la Administración una mera «discrecionalidad instrumental» en la aplicación de los conceptos jurídicos indeterminados, es decir, el sujeto «opera» discrecionalmente pero no tiene «discrecionalidad», frente a la «discrecionalidad fuerte» predicable de aquellos actos en los que no sólo «opera» discrecionalmente sino que tiene «discrecionalidad» ${ }^{44}$.

La distinción, suficientemente conocido es y se ha apuntado mas arriba, tiene asociado un debate importante relacionado con el control que de los actos de la Administración puedan efectuar los jueces y viene acompañada de la necesidad de concretar en cada caso el interés público que justifica la actuación administrativa, pues no olvidemos que conforme al artículo 9.3 de nuestra Constitución esta garantiza la interdicción de la arbitrariedad de los poderes públicos y que el artículo 103.1 reafirma que la Administración sirve con objetividad a los intereses generales, intereses generales que deben entenderse no como «principio» justificador de la existencia de la propia Administración, sino como «concepto legal» que exige una interpretación y aplicación condicionada por la norma que lo emplea y por las circunstancias de cada caso ${ }^{45}$.

\footnotetext{
42 Juan Igartua SALAVERRía, «Principio de legalidad, conceptos indeterminados y discrecionalidad administrativa, en Revista Española de Derecho Administrativo, $\mathrm{n}^{\circ} 92$.

${ }^{43}$ M. Bacigalupo, La discrecinalidad administrativa, cit., página 204.

${ }^{44}$ Eva Desdentado Daroca, Discrecionalidad administrativa, cit., páginas 52 y 133.
} 
Por tanto si hablamos de las Normas de Aplicación Directa como preceptos jurídicos que dan lugar a la aplicación inmediata de la Ley del Suelo sin necesidad de normas o instrumentos de planificación intermedios podemos concluir que en estos casos es posible que tales normas:

1. Sirvan como norma de Derecho necesario de aplicación automática, conteniendo en su estructura conceptos jurídicos determinados de aplicación inmediata.

Dentro de estas podemos incluir todas aquellas que establecen obligaciones inmediatas, cualitativa y cuantitativamente determinadas que posibilitan la aplicación inmediata de la Ley para la adopción de actos administrativos.

2. Establezcan prescripciones de ordenación conteniendo en su estructura conceptos jurídicos indeterminados, dada la generalidad de las situaciones a las que se dirigen, que deben concretarse por la Administración en cada caso de aplicación directa de la Ley del Suelo atendiendo a las circunstancias de hecho que concurran, en tales situaciones la Administración debe necesariamente completar la «zona de incertidumbre» atendiendo a criterios de racionabilidad, proporcionalidad y oportunidad, pero en todo caso actúa dentro de un estrecho margen cuya función es fijar el supuesto de hecho justificativo de la aplicación de la norma, ese margen puede ser completado mediante la integración de criterios valorativos, pero también puede tener carácter técnico por lo que en tal caso su control depende del margen de apreciación que el área de conocimiento de la técnica aplicable permita.

3. No sería admisible que las Normas de Aplicación Directa fijaran en este apartado parámetros dentro de los cuales pueda ejercerse la discrecionalidad administrativa, entendiendo como tal la posibilidad de dictar actos administrativos no reglados, es decir de actuar sobre el elemento «decisión» de la estructura normativa, precisamente porque su finalidad es la de permitir el ejercicio de los derechos de propiedad urbanísticos, cuya característica determinante es el carácter reglado de las licencias.

\subsection{EI Planeamiento como delimitador de la zona de incertidumbre de las normas de aplicación directa}

\footnotetext{
${ }^{45}$ Fernando Sáinz MoReno, «Reducción de la discrecionalidad: El interés público como concepto jurídico», Revista Española de Derecho Administrativo, nº 8 .
} 
Ya hemos señalado anteriormente que otra de las funciones asignables a las Normas de Aplicación Directa es la de contener mandatos dirigidos al planificador al objeto de que este, en ejercicio de la potestad concedida por el ordenamiento jurídico, recoja dentro de otras normas de carácter derivado los elementos de protección objeto de las Normas de Aplicación Directa.

La potestad de planificación es, o ha sido posiblemente hasta estos momentos, la que mayor margen de maniobra permite a los municipios para la libre configuración normativa, no solo en cuanto a su extensión sino en cuanto a sus efectos ${ }^{46} \mathrm{y}$, en este sentido, es proverbial la cita que se efectúa de la STS de 1 de diciembre de 1998 (Aranzadi 9708) cuando señala que:

No ofrece dudas el carácter discrecional del planeamiento, discrecionalidad que comporta un formidable poder en manos de la Administración municipal, puesto que, en definitiva, de dicha discrecionalidad depende el alcance concreto del derecho de propiedad a ejercer en cada parcela del territorio municipal 47.

Es ciertamente la discrecionalidad del planeamiento un elemento proverbial del mismo y así se ha dicho que esta se plasma tanto a la hora de elegir los objetivos como de concretar sobre el terreno las determinaciones que el plan ha de establecer para los distintos elementos que debe ordenar, por lo que son muchísimas y muy diferentes las soluciones posibles ${ }^{48}$, soluciones que obviamente no descansan sobre la voluntad de un único sujeto y de un sector del ordenamiento jurídico, pues sobre el territorio confluyen las competencias de varias Administraciones y sobre el mismo se plasman gran número de determinaciones contenidas en diversas ramas del ordenamiento jurídico, pues necesariamente se parte de directrices legales muy genéricas cuya concreción en cada punto exige calibrar un gran cúmulo de intereses públicos y privados y efectuar valoraciones que van mas allá de los que es propio de un juicio técnico y que presuponen o llevan consigo otras opciones de naturaleza primariamente política ${ }^{49}$, pero que tiene un eje central que es el municipio y el ente que lo representa, es decir, el Ayuntamiento caracterizado en su funcionamiento por el reconocimiento que de su autonomía ha efectuado la Constitución.

\footnotetext{
${ }^{46}$ Enrique SÁNChez Goyanes, La potestad normativa del municipio español, Madrid, Ed. El Consultor, 2000, página 332 .

${ }^{47}$ Citado por Enrique SÁnchez GoyAnes, La potestad normativa. cit., página 333.

48 Javier Delgado Barrio, El control de la discrecionalidad del planeamiento urbanístico, Madrid, Ed Civitas, 1993, página 19.

49 Tomás Ramón Fernández, De la arbitrariedad de la Administración, cit., página 52.
} 
No debe olvidarse, no obstante, que la potestad de Planeamiento deriva de la Ley y de la misma obtiene la legitimidad para su creación, en tal sentido es conocido que dentro del desarrollo de la legislación en cascada que es tradicional en los sistemas jurídicos las normas primarias establecen obligaciones de desarrollo de las de carácter secundario, prefigurando las mismas pero dejando siempre un cierto margen a éstas; en este sentido, a lo largo de este proceso de concreción se ha señalado la producción de un doble efecto, por una parte, la aplicación de la norma superior y, por otra, la creación de una norma, en este doble juego de la aplicación-producción el órgano competente tiene siempre un cierto margen de conformidad de la realidad, es decir, una «esfera para el ejercicio de la discrecionali$\mathrm{dad} \gg{ }^{50}$.

La mayor o menor discrecionalidad del órgano dependerá, por una parte, del carácter de la norma que crea y, por otra, del mayor o menor campo de libertad que le dé la norma que aplica, en tal sentido se ha señalado la diferencia necesaria existente entre los reglamentos ejecutivos, los independientes y los necesarios y la menor discrecionalidad predicable de los primeros frente a los segundos ${ }^{51}$.

El Planeamiento no puede, sin embargo, configurarse como un reglamento ejecutivo de la Ley del Suelo y, en consecuencia, no puede del mismo predicarse en sentido estricto la relación norma legal-desarrollo ejecutivo mediante norma reglamentaria, ciertamente del Plan puede señalarse su carácter de norma reglamentaria pues son elementos normativos ordenadores de la realidad con vocación de vigencia indefinida, se destina a una pluralidad indeterminadas de destinatarios y su cumplimiento no implica agotamiento o consunción, pero, por otra parte, no sería un reglamento ejecutivo ${ }^{52}$ pues su finalidad no es completar o desarrollar de forma pormenorizada la Ley del Suelo, no hay desarrollo sino aplicación de la Ley con la finalidad de ordenar urbanísticamente un territorio, por tanto plasma sobre el mismo las determinaciones genéricamente establecidas en la Ley, en consecuencia el ámbito de discrecionalidad que el planificador

\footnotetext{
${ }^{50}$ Eva Desdentado Daroca, Discrecionalidad Administrativa y..., ob. cit., página 95.

${ }^{51}$ Eva Desdentado Daroca, Discrecionalidad Administrativa y..., ob cit., página 96.

52 No obstante no ser un reglamento ejecutivo, podríamos definir los mismos como «remitidos» conforme señala J. ToRnos MAS en «La relación entre Ley y el Reglamento: reserva legal y remisión normativa, algunos aspectos conflictivos a la luz de la jurisprudencia constitucional», en R.A.P nº 100-102 de 1983 página 486, en este mismo sentido lo efectúa Antonio Alfonso Pérez ANDRÉs, «La limitación constitucional de la remisión legislativa al planeamiento (hacia la reducción de la discrecionalidad)», Revista de Derecho Urbanístico, número 146, edición electrónica, que denomina al mismo como reglamentos conformadores.
} 
dispone es medio ${ }^{53}$, pero se ve limitado ciertamente por la norma y por el fin de ésta, pero en ningún caso puede derivarse la existencia de una única alternativa al planificador ${ }^{54}$.

En todo caso, la posibilidad de que el Planeamiento tenga un mayor o menor ámbito de libertad para configurar sus contenidos dependerá, por una parte, de la densidad normativa ${ }^{55}$ recogida en las Leyes reguladoras de la ordenación urbanística y del contenido del derecho de propiedad, pero igualmente del reconocimiento de un ámbito de regulación propio derivado del reconocimiento constitucional de la autonomía local, lo que ciertamente no puede suponer ni la creación de un ámbito exento de control ni la posibilidad de creación de una norma reglamentaria independiente de la Ley.

Puede afirmarse, en suma, que como cualquier potestad reglamentaria, en su ejercicio nos encontraremos tanto límites formales como sustanciales, de los primeros pueden predicarse la competencia para dictar el plan, el necesario procedimiento que hay que seguir para elaborarlo, y el respeto al principio de jerarquía normativa, en cuanto a los límites sustanciales podemos destacar el respeto a los principios generales del Derecho, interdicción de la arbitrariedad de los poderes públicos, la proporcionalidad y la racionalidad y razonabilidad en toda actuación administrativa; pero además estará sujeta, como toda potestad discrecional a las distintas técnicas del control de la discrecionalidad administrativa; $y$, como se ha señalado a la restricción de su ámbito material por la Ley ${ }^{56}$, condición que de forma

\footnotetext{
53 Juan DE LA CRUZ FerRer, «Sobre el control de la discrecionalidad en la potestad reglamentaria», en Revista de Administración Pública, nº 116, mayo-agosto 1988, página 71.

${ }^{54}$ En este sentido se pronuncia la sentencia del TSJ de Cantabria de 1 de junio de 1999 ( Aranzadi RJCA 1999\3288) respecto a los P.O.R.N derivados de la Ley 4/1989, de 27 de marzo, en igual criterio que para los Planes Generales.

\begin{abstract}
${ }^{55}$ Antonio Alfonso Pérez ANDRÉs, «La limitación constitucional de la remisión legislativa al planeamiento (hacia la reducción de la discrecionalidad)», R.D.U cit., edición electrónica, afirma en este sentido que:

En conclusión, en la densidad normativa de la Ley está la medida de constitucionalidad de la remisión al planeamiento. Ésta habrá de ser máxima para cumplir con la reserva de la limitación del derecho de propiedad a la Ley, tal y como la hemos venido defendiendo; pero a pesar de ello, en virtud de la naturaleza propia del objeto normado (la propiedad inmueble), llega un momento en que la reserva cesa, lo que ocurre antes en esta materia que en otras esferas de la reserva material como son el derecho administrativo sancionador o la normativa tributaria. Desde ese momento será posible completar la regulación haciendo uso de la técnica de los reglamentos remitidos, aunque para ello la Ley de remisión deberá contener, hasta donde sea posible, los principios y criterios a los que habrán de ajustarse los planes, previendo al menos la afección a los derechos y deberes de los ciudadanos que éstos puedan tener.
\end{abstract}


necesaria debe igualmente plasmarse cuando a lo que nos referimos es a los conceptos jurídicos indeterminados y a su halo de incertidumbre.

Si la Ley pretende un control de la discrecionalidad de la que el planificador dispone, necesariamente debe tender a una mayor densidad normativa de sus principios, que pueden llegar a actuar directamente como normas de planeamiento, eliminando con ello la posible discrecionalidad que inicialmente es atribuible al planificador, de tal manera que acote el ámbito de actuación o de decisión de este y en consecuencia y ante la imposibilidad de que desde la Ley pueda establecerse una ordenación detallada de los terrenos, dada la multitud de situaciones que se plantean en la realidad, es preciso que ésta acuda al establecimiento de conceptos jurídicos indeterminados.

En este caso el planificador ve limitada sus potestades exclusivamente a la fijación de los elementos que concretan el «halo o zona de incertidumbre» del supuesto de hecho que la ley no puede determinar, concretando con ello el presupuesto de aplicación de la norma, pues las consecuencias de la existencia del supuesto de hecho se encuentran predeterminadas en la Ley bien directamente o mediante el uso de conceptos jurídicos indeterminados igualmente, debiendo tener presente que cuando la Administración ha dictado un reglamento, para el cual dispone de una cierta discrecionalidad, los actos aplicativos del mismo son actos de ejecución sobre los que no debe existir discrecionalidad ${ }^{57}$.

Por tanto, mediante las Normas de Aplicación Directa el legislador limita la discrecionalidad del planificador haciendo que ésta se mueva dentro de la zona neutra o «halo de incertidumbre» de los conceptos jurídicos indeterminados contenidos en las Normas de Aplicación de Directa, pues éstas al ser prevalentes sobre el Planeamiento no pueden ser objeto de omisión o regulación contraria a la Ley, de tal manera que a partir de su plasmación y en razón de la vinculación positiva de la Administrativa a la Ley y del carácter reglado de las licencias se superen las indeterminaciones que puedan plantearse en la aplicación de los conceptos jurídicos indeterminados.

Dado el carácter preeminente de las Normas de Aplicación Directa sobre el planeamiento éste no tiene otra función que concretar las mismas

\footnotetext{
${ }^{56}$ Antonio Alfonso Pérez AndRÉs, «La limitación constitucional de la remisión legislativa al planeamiento (hacia la reducción de la discrecionalidad)», R.D.U cit., edición electrónica.

${ }^{57}$ Alfredo Gallego Anabitarte y Ana de Marcos Fernández en Derecho Administrativo I, materiales. citado por M. BACIGALUPO en La discrecionalidad administrativa, cit., página 84.
} 
por lo que la contradicción entre las Normas recogidas en la Ley y su concreción en el planeamiento no dan lugar a un predominio de este último, sino a la aplicación directa de las primeras, pues el Plan no puede articular un conjunto de obligaciones distintas a las recogidas en las Normas, sino que su función es meramente concretarlas, en este sentido cuanto mayor sea la densidad normativa que pueda desprenderse de las Normas de Aplicación Directa menor será la discrecionalidad que dispondrá el planificador para la conformación de las soluciones del Plan.

El planeamiento, por tanto, tiene como función concretar mediante la adopción de una decisión «volitiva» de la Administración el ámbito atribuible a la zona de incertidumbre y en consecuencia a partir de esa fijación la actuación que realiza la Administración en aplicación del planeamiento ya no dispone de una zona neutra alguna sino que es exclusivamente un acto reglado.

\section{LAS NORMAS DE APLICACIÓN DIRECTA EN LA LOTRUSC}

Procede, en suma, analizar ya dentro de la Ley de Cantabria 2/2001, de 25 de junio, cuáles son las que ésta configura como Normas de Aplicación Directa y concretar el régimen jurídico de la protección del paisaje a fin de poder analizar, dentro de las alternativas recogidas anteriormente, cuál es la funcionalidad esperada de las mismas.

A este efecto la Ley cántabra las establece dentro del Título I de la Ley, bajo el epígrafe de «Planeamiento Territorial y Urbanístico: Instrumentos de Ordenación», al Capitulo III, denominado «Planeamiento Urbanístico», la Sección 2 denominada de «Normas de Aplicación Directa y Estándares Urbanísticos en el Planeamiento Municipal» recogiendo dicha ordenación dentro de los artículos 32 a 42.

Ya la exposición de motivos, tras reconocer el difícil mapa municipal existente con un gran número de municipios de escasa población y limitados planeamientos urbanísticos, manifiesta que: Estos datos conducen a establecer diferencias y posibilidades para unos y otros municipios. Menos exigencias en el planeamiento de los municipios pequeños, pero, a cambio, mayores previsiones de aplicación directa en la Ley.

Esta declaración recoge en si el principio pretendido de preconfiguración por la Ley de las posibles alternativas a adoptar por el planeamiento municipal y en consecuencia la limitación del ámbito de decisión otorga- 
da a aquel, de esta forma la exposición de motivos ratifica que: Ello no obstante, hay, sí, un mínimo de aplicación directa, que es variado y que en ocasiones puede ser modificado por el Gobierno.

Su finalidad declarada es limitar la discrecionalidad municipal mediante las Normas y establece que: La flexibilidad de contenidos del planeamiento general resulta compensada con la previsión de normas protectoras más intensas, las normas de aplicación directa — que se imponen por sí mismas, con o sin Plan, y que, en todo caso, condicionan a éstos-y los estándares urbanísticos —que, aunque no son de aplicación directa, se imponen también al planeamiento municipal-. Ahí queda resguardado y protegido el ámbito o núcleo mínimo legal, el denominador normativo común a partir del cual el planificador municipal podrá ampliar las exigencias, pero no reducirlas.

Declaración que se reitera en la exposición de motivos indicando la importancia que el legislador atribuye a estas Normas cuando declara que Descendiendo ya al plano estricto del urbanismo cabe mencionar, en primer y principal lugar, las normas de aplicación directa de la Ley (que rigen y se imponen en todo caso, tanto si hay planes como si no los hay) y los estándares urbanísticos (que no rigen directamente, pero condicionan el planeamiento dado que éste no puede prescindir de ellos). Aquí se contiene el marco normativo material y sustantivo, que es clave en toda la Ley. A partir de esos mínimos los contenidos dependen efectivamente del planeamiento municipal, respecto del cual la Ley se limita a posibilitar opciones.

Afirmación de la exposición de motivos que es objeto de contundente reafirmación en el artículo 42 de la LOTRUSC mediante el cual: En todo lo no previsto en los artículos anteriores de aplicación directa, se estará a lo dispuesto en el planeamiento municipal y, en su ausencia, a las Normas Urbanísticas Regionales o Comarcales que apruebe el Gobierno de Cantabria.

Si bien, como se ha señalado, las normas de aplicación directa pueden tener por finalidad recoger los principios inspiradores del planeamiento establecidos en el artículo 3 de la Ley de Cantabria ${ }^{58}$, no es menos cierto que de las mismas, conforme al artículo 42 de la LOTRUSC, se predica su carácter de norma prioritaria sobre el Planeamiento Municipal, el cual es aplicable exclusivamente en lo no previsto en las Normas de Aplicación de

\footnotetext{
${ }^{58}$ Miriam García GarCíA, «Determinación de la ordenación urbanística. El Planeamiento Urbanístico General» en vol. col. dirigido por Enrique SÁNChEz GoYANES, Derecho Urbanístico de Cantabria, Madrid, Ed. El Consultor, 2002, pág. 174.
} 
Directa, y en caso de no existir éste actuará de forma supletoria lo establecido en las Normas Urbanísticas Regionales o Comarcales que apruebe el Gobierno de Cantabria, lo que implica claramente que dicha normativa de planeamiento se encuentra subordinada a las Normas de Aplicación Directa y que estas se constituyen como límites a la potestad de planeamiento de los entes locales que necesariamente en su desarrollo deben atenerse a las mismas, no obstante, esa limitación es, en la mayoría de los casos, de difícil concreción dada la generalidad e indeterminación de los elementos sobre los que se sostiene.

En consecuencia, podemos señalar que si bien es verdad que el planificador goza de cierto margen en cuanto a la fijación de las técnicas en las que ha de plasmarse la protección a desarrollar, sin embargo, la determinación de las zonas objeto de protección obedece a ciertos criterios objetivables determinados no solo por la legislación urbanística, de lo que se desprende que los mismos merecen ser tratados como tales aunque no hayan sido objeto de una previa declaración oficial, por lo que el planeamiento no tiene otra función que concretar y pormenorizar los elementos que determinan dicha protección, ahora bien, tal afirmación no excluye la existencia de un previo problema de acreditación de los hechos determinantes que obligan a la aplicación de la norma, así como de la posible concurrencia con los mismos de un cierto margen de apreciación en manos de la Administración de cara a determinar la concurrencia o no de dichos requisitos.

Procede por tanto efectuar el análisis de los artículos dedicados a la protección del paisaje,

\subsection{Protección del entorno cultural}

El artículo 33 de la Ley de Cantabria 2/2001, es heredero del artículo 138, a) del RD Leg 1/1992 de 26 de noviembre, si bien introduce diversas matizaciones en cuanto los objetos de protección, y así viene a establecer:

1. Sin perjuicio de lo dispuesto en el artículo anterior y en la legislación que resulte aplicable, las construcciones en lugares inmediatos o que formen parte de un grupo de edificios de carácter histórico o cultural formalmente declarados como tales conforme a la normativa sectorial específica o que estén incluidas en Catálogos propios del planeamiento municipal, habrán de armonizar con el entorno, especialmente en cuanto a alturas, volumen y materiales exteriores.

2. El planeamiento municipal incluirá las previsiones necesarias para la conservación y realce del patrimonio cultural, con especial referencia a los espacios urbanos relevantes, hayan sido o no catalogados de acuerdo con otra legislación secto- 
rial de protección. Los Planes Generales velarán asimismo por la conservación de la trama urbana en los núcleos tradicionales ${ }^{59}$.

El artículo 33 establece como criterios de protección del entorno cultural, en primer lugar, la armonización en los lugares inmediatos a grupos de edificio de carácter histórico o cultural, recogido anteriormente en el artículo 138 a) del RD Leg 1/1992 de 26 de junio, si bien limita su actuación a dos situaciones: cuando los edificios se encuentra formalmente declarados como tales conforme a la normativa sectorial ${ }^{60}$ o cuando se encuentre dentro de los catálogos del planeamiento.

A los efectos de este artículo podemos entender como entorno, en aplicación del artículo 50 de la Ley de Cantabria 11/1998, del Patrimonio Cultural: el espacio, edificado o no, próximo al bien, que permite su adecuada percepción y comprensión, considerando tanto la época de su construcción, como su evolución histórica, que da apoyo ambiental y cultural al mismo y que permite la plena percepción y comprensión cultural del bien y cuya alteración puede afectar a su contemplación o a los valores del mismo, entorno que de conformidad con dicha Ley debe establecerse junto con la declaración del bien como BIC o Bien de Interés Local, pero que no se predican del resto de categorías, de protección, tales como los Bienes Inventariados, o de los recogidos en el Catalogo del Plan.

En consecuencia, nos encontramos con una situación distinta de la planteada en el artículo 73 del Texto Refundido de 1976 y 138 del RD Leg 1/1992, pues estos conforme a la STS de 16 de junio de 1993 (Aranzadi RD 1993\4884) ${ }^{61}$ eran aplicables:

sin que sea necesario esa pertenencia al casco antiguo, porque la Ley no distingue; ni es necesaria una declaración previa de conjunto histórico artístico - SS. 6 julio y 30 junio 1982 (RJ 1982\5344 y RJ 1982\5246)—; y aunque el edificio o conjunto

\footnotetext{
${ }^{59}$ Debe hacerse notar que el proyecto de Ley introducía dos apartados que fueron retirados en razón de las alegaciones presentadas por la Federación de Municipios de Cantabria el primero de ellos señalaba que «como regla no podrán realizarse construcciones de nueva planta a menos de 50 metros de un edificio declarado bien de interés cultural con la categoría de monumento», y el apartado 3 establecía que «las excepciones a lo dispuesto en este precepto habrán de ser pericialmente justificadas y, de no existir figura urbanística aprobada de conformidad con la legislación de patrimonio cultural, necesitarán la autorización expresa de la Consejería competente en materia de cultura, que deberá ofrecer un trámite de información pública no superior a un mes con anterioridad a su decisión».

${ }^{60}$ En este caso la Ley 16/1985 de 25 de junio, del Patrimonio Histórico Español y la Ley de Cantabria 11/1998, de 13 de octubre, del Patrimonio Cultural de Cantabria.

${ }^{61}$ En el mismo sentido la STS de 6 de julio de 1982 (Aranzadi Rj 198215344).
} 
de edificios en que concurran los valores que la norma trata de proteger - art. 73 del Texto Refundido de la Ley del Suelo y art. 98.2 del Reglamento de Planeamiento- no se encuentren incluidos en los correspondientes Catálogos, pues de no ser así carecería de sentido que los mentados preceptos precisen con todo detalle los caracteres que deben reunir aquéllos para que las construcciones en lugar inmediatos a los mismos deban adaptarse, en lo básico al ambiente en que estuviesen situados haciendo referencias a edificios de carácter artístico, histórico, arqueológico, típico o tradicional [SS. 20 abril y 11 febrero 1985 (RJ 19852214 y RJ 1985\1015) y 31-3-1989 (RJ 1989\2444)]; precepto de aplicación directa, existan o no probados Planes de Ordenación o Normas Complementarias y Subsidiarias de Planeamiento,

En el presente caso la aplicación de la norma exige una previa declaración de catalogación oficial del Bien o la inclusión en el Catalogo, lo que supone indudablemente un incremente en la seguridad jurídica, pero, tal como se señaló anteriormente, no deja de suyo que nos encontremos para su aplicación ante conceptos jurídicos indeterminados de necesaria concreción, tal como señala la STS de 8 de noviembre de 1990 (Aranzadi RJ 1990\8820) ${ }^{62}$.

No obstante, no nos encontramos con una prohibición de construcción, conforme a la STS de 16 de junio de 1993 (Aranzadi RD 1993\4884), sino con una limitación relativa en la medida que se impone a los propietarios la necesaria armonización con el conjunto de edificios colindantes que, merecedores de su valor cultural, deben reunir un entorno adecuado que permita su contemplación ${ }^{63}$.

La norma en su primitiva redacción, alterada en el documento finalmente aprobado, pretendía garantizar una interpretación uniforme median-

\footnotetext{
${ }^{62}$ Esta sentencia señala que: los artículos 73 del Texto Refundido de la Ley del Suelo y 98 del Reglamento de Planeamiento contienen una regla sustantiva de ordenación directamente aplicable, y pueden por ello ser invocados por los Ayuntamientos para fundamentar denegaciones de licencia de obras, y si bien es cierto que las expresiones recogidas en los mismos encierran, como señala la sentencia de 31 de diciembre de 1988 (RJ 1988V10293) de la antigua Sala 4. ${ }^{a}$, «conceptos jurídicos indeterminados de indudable naturaleza reglada, lo que excluye toda discrecionalidad -incompatible con la naturaleza de la licencia urbanística-, aunque desde luego en su aplicación ha de reconocerse a la Administración un cierto margen de apreciación en razón del halo de dificultad que caracteriza el espacio de incertidumbre que media entre las zonas de certeza positiva y negativa»,

${ }^{63}$ La sentencia establece expresamente que:

se trata de una limitación del «ius aedificandi» no absoluta, sino relativa, en cuanto sólo impone una carga modal, permitiendo la edificación, pero sólo cumpliendo determinadas condiciones, aquellas que permitan la armonización de la nueva construcción con el conjunto de edificios, o el edificio, merecedores, por su valor histórico-artístico o arqueológico, de reunir un entorno adecuado a los mismos, eliminando los proyectados sin otras miras que las simplemente utilitarias y funcionales;
} 
te dos criterios, el primero de ellos estableciendo una regla general, aunque no de aplicación universal, cual era la predeterminación del ámbito físico del entorno de un edificio declarado de interés cultural, que fijaba en 50 metros, y en segundo lugar estableciendo la necesaria obligación de que las excepciones fuesen «pericialmente» justificadas.

La primera de las soluciones proponía una solución a problema de indeterminación pues ni fijaba de forma definitiva ni era realmente posible concretar de antemano lo que puede estimarse como entorno de un bien cultural, por lo que fue retirado del proyecto, en el segundo caso la norma planteaba que los conceptos indeterminados como entorno, ambiente o armonización no son conceptos que dependen de la voluntad del que los interpreta, sino que deben ser objeto de una determinación universalmente aceptable, por lo que podía ser remitida su apreciación a la valoración experta de un «perito», criterio que tiene su base en las propias declaraciones jurisprudenciales, ya que éstas han mantenido que la aplicación de estos conceptos jurídicos indeterminados no pueden estar basados en criterios subjetivos de los miembros de la Corporación Municipal, sino que deben resolverse atendiendo a elementos de juicio de carácter técnico o estético que se sustentan por dictámenes, o que dimanen del proyecto formulado por el instante del expediente ${ }^{64}$.

No obstante, no puede afirmarse en estos momentos que esta «pericia» corresponda exclusivamente a una profesión, arte u oficio, por lo que la introducción de la misma suponía mas confusión que claridad, por lo que este apartado fue retirado del proyecto finalmente aprobado.

Por otra parte, el apartado segundo del artículo 33 establece la necesidad de incluir en el Planeamiento las previsiones necesarias para la conservación y realce del patrimonio cultural, así como de los espacios urbanos relevantes hayan sido o no catalogados de acuerdo con la legislación sectorial ${ }^{65}$, con obligación de conservación de la trama urbana en los núcleos tradicionales ${ }^{66}$, en consecuencia, el mismo se dirige al ejercicio por la entidad local de su potestad de planeamiento en aplicación del

\footnotetext{
${ }^{64}$ Así se recoge en la STS de 14 de Noviembre de 1986 ( Aranzadi RJ 198618082) con respecto al artículo 73 b) del Texto Refundido de 1976

${ }^{65}$ Debe entenderse que la protección que se dispensa lo es a aquellos bienes en que pese a concurrir los requisitos para ser incluidos dentro de los registros, catálogos o inventarios no hayan sido objeto aún de declaración formal conforme a la normativa sectorial, por lo que tal protección exigirá al Ayuntamiento o a la Comunidad Autónoma instar tal declaración o inscripción que no de no producirse impediría la inclusión de los criterios de protección dentro de esta norma, la remisión al «Patrimonio cultural» así lo confirma salvo que se pretenda la existencia de una «patrimonio cultural» situado fuera de la Ley 11/98 de Patrimonio Cultural de Cantabria, lo que no parece de recibo.
} 
mismo juego señalado en el artículo 32 de recoger su aplicación no sólo en los casos de licencias en ausencia de plan, sino de la necesaria plasmación de sus determinaciones en el planeamiento urbanístico municipal cuya misión debe ser, como se ha incidido anteriormente, precisamente la de limitar el ámbito de incertidumbre de cara a la ejecución del planeamiento.

En aplicación de esta obligación el artículo 44, d) de la LOTRUSC establece que el Planeamiento debe contener como determinación mínima el catálogo de elementos arquitectónicos o naturales que deben ser conservados e identificación de las medidas de protección que procedan, sin perjuicio además de los que deban asimismo catalogarse de conformidad con la legislación del Patrimonio Cultural, pero sin embargo el artículo 33 añade un plus sobre dicha obligación en el sentido de exigir «el realce» del patrimonio cultural, lo que obliga a una actuación positiva del planificador que debe establecer, necesariamente, como uno de sus objetivos dicha mejora en la percepción del bien patrimonial.

Debe recalcarse aquí que dentro del Patrimonio Cultural es objeto de especial referencia los «espacios urbanos relevantes», hayan sido o no recogidos, aún debería añadir la norma, en la legislación sectorial, y que debe interpretarse conforme al apartado primero de este artículo como necesariamente catalogados en el Plan, que no pueden equipararse de forma única con las edificaciones pues su sentido es mas amplio.

Aquí volvemos a encontrarnos con los problemas tradicionales de las Normas de Aplicación Directa y relativos a la concreción al caso concreto de los conceptos jurídicos indeterminados contenidos en la norma y a si esta permite la existencia de un ámbito para la aplicación de la discrecionalidad administrativa.

Hemos de partir que del hecho de que en el presente artículo la situación de hecho previa a la aplicación de la norma requiere de un acto de la Administración anterior a su aplicación, la protección del bien a través de las técnicas recogidas en la legislación sectorial del Patrimonio Cultural o la inclusión en el Catálogo del Plan, en tales casos la norma exige que la

\footnotetext{
${ }^{66}$ El proyecto inicial incluía la protección de la trama urbana también los supuestos de rehabilitación, retirándose del proyecto definitivo en razón de una alegación presentada por la FMC, siendo justificada tal retirada en que respecto de la objeción acerca de la exigencia de mantener la trama urbana en los supuestos de rehabilitación. Esa trama, en efecto, debe ser protegida en los núcleos tradicionales, pero la Ley —otra cosa es lo que digan los concretos Planes- no tiene por qué limitar tanto la creatividad en los supuestos de rehabilitación».
} 
nueva construcción «armonice» con las previamente existentes, esta función se realiza a través de dos técnicas fundamentales:

a. El mantenimiento de volúmenes de construcción y tipologías análogas a las existentes.

b. El uso de materiales y colores semejantes a los de las construcciones cercanas.

Si se cumplen estas condiciones podemos afirmar que existe una condición suficiente para entender que se produce una armonización, pero las mismas no contienen los elementos oportunos para considerarlos igualmente necesarios, por tanto, podemos decir que si los mismos concurren se produce la aplicación positiva de la norma, y si no concurren ésta no se produce, es decir, nos encontraríamos en la zona negativa de aplicación de la norma, pero en todo caso entre la zona positiva y la negativa existe ciertamente una zona de incertidumbre, no muy amplia, pero que requiere una previa determinación de los conceptos, entre ellos el de la ubicación de los volúmenes nuevos con respecto a los ya existentes, zona que puede limitarse cuando la Administración establece con carácter previo aquellas circunstancias o elementos que de producirse dan lugar a la «armonización» con el entorno.

No obstante, no existe en este artículo discrecionalidad alguna a favor de la Administración en cuanto a las posibles consecuencias de la norma, pues esta no puede adoptar varias soluciones, sólo puede adoptar una, la que «armonice» con el entorno, es decir, no puede establecer una norma con «cópula», lo que supone la decisión de aplicar o no aplicar la misma ya que ésta es de obligada aplicación por la Administración, y tampoco puede fijar un nuevo objetivo a alcanzar, pues éste viene predeterminado por una situación anterior que es la que tiene que conservar, de lo que se deriva que no existe posibilidad de transformación de la misma ni de decisión del modelo final que sería en el que se plasmaría la discrecionalidad de la Administración.

Por último, el artículo 33 plantea la necesidad de proteger la trama de los núcleos tradicionales, si bien la Ley omite qué debe entenderse por núcleo tradicional, debiendo estimar por tal aquel que ha recogido los asentamientos ligados al desarrollo histórico de un núcleo urbano caracterizado por su permanencia en el tiempo y por un conjunto inmobiliario con características comunes históricas, etnológicas o artísticas, núcleo tradicional que no necesariamente debe entenderse limitado a los de carácter 
rural sino también a los denominados «cascos históricos» de las poblaciones de mayor tamaño.

El concepto de núcleo tradicional es indudablemente un concepto jurídico indeterminado en el que el halo de decisión se centra en la posibilidad de considerar el conjunto de edificios como tal núcleo o como meros elementos aislados en función de las características que concurran, y la limitación de respeto a la trama urbana una limitación directa sobre el planeamiento que no permite considerar la existencia de un ámbito de discrecionalidad, ya que el planificador no es libre en la elección entre conservación y transformación y que plantea obviamente una decisión legislativa sobre la conservación frente a la reforma, decisión que se impone al planificador de forma directa y que le obligará al mantenimiento de la situación preexistente en una nueva manifestación de la «fuerza normativa de lo fáctico».

\subsection{Protección del paisaje}

El artículo 34, en su apartado primero reproduce el artículo 138 b) del RD Leg 1/1992, de 26 de junio, en su exigencia de adaptación al ambiente, a su vez heredero directo y fiel del artículo 73 b) del Texto Refundido de 1976, con cuatro limitadas modificaciones, así se elimina la exigencia de que el paisaje sea rural o marítimo, pues obviamente no aporta en sí nada relevante, sobre todo teniendo en cuenta que no se produce su omisión sino más bien su sustitución por una ubicación diferente dentro del artículo, la otra modificación consiste en la adicción de la necesidad de que en el presente caso «se acentuarán las exigencias de adaptación al ambiente de las construcciones que se autoricen», la tercera de ellas en la inclusión de los «colores» como elemento de exigencia de adaptación al ambiente y la última consiste en la obligación que no se rompa la armonía del paisaje «natural, rural o urbano».

Partiendo del carácter básico del artículo 138, b) del RD Leg 1/1992, de 26 de junio, lo que indudablemente plantea la innecesariedad de su reiteración en la norma autonómica pues su validad lo es no por su incorporación a la LOTRUSC sino por su incorporación a la norma estatal, es preciso analizar, al hilo del estudio del presente artículo, si tales incorporaciones añaden algo más, es decir, si estas introducen un plus sobre las obligaciones derivadas de la norma estatal.

La dificultad de interpretación de esta norma ha sido proverbial hasta para el Tribunal Constitucional, el cual en su sentencia 148/1991, de 4 de 
julio (Aranzadi RTC 1998\148) ha señalado con referencia al artículo 73 del Texto Refundido de 1976 que: No es impertinente recordar que esta norma de la Ley del Suelo, cuyo grado de indeterminación es evidente, constituye una norma sustantiva directamente aplicable a todas las construcciones que se lleven a cabo en cualquier lugar del territorio nacional, independientemente de que el mismo esté o no sometido a un plan de ordenación urbanístico, y al margen de que esté calificado como suelo urbano, urbanizable o no urbanizable y su justificación sectorial se encuentra en la protección del medio ambiente ${ }^{67}$ debiéndose distinguir del resto de la normativa sectorial pues como señala la STS de 24 de octubre de 1990 (Aranzadi RL 1990\8329), los conceptos de lugares del paisaje abierto y natural, sea rural o marítimo, o las perspectivas que ofrezcan los conjuntos urbanos de características histórico-artísticas, típicos o tradicionales, o en las inmediaciones de las carreteras y caminos de trayecto pintoresco «son conceptos no coincidentes con los correspondientes de la legislación sobre el patrimonio histórico-artístico, espacios naturales o turística, en que sería ésta la que disciplinase, al objeto de prohibirlas».

No obstante, debe recordarse aquí la jurisprudencia anteriormente indicada, y recogida a modo de ejemplo en la del Tribunal Supremo de 8 de noviembre de 1990 (Aranzadi RJ 199018820), que establece el carácter de concepto jurídico indeterminado contenido en la norma, sin perjuicio de lo cual ha de reconocerse a la Administración un cierto margen de apreciación en razón del halo de dificultad que caracteriza el espacio de incertidumbre que media entre las zonas de certeza positiva y negativa ${ }^{68}$, pero no obstante lo cual la jurisprudencia declara a menudo que los concepto jurídico indeterminado dan lugar a una única solución, así lo señala la STS de 21 de Noviembre de 2000 (Aranzadi RJ 2000\10267).

La jurisprudencia citada por el recurrente alude a que la sustitución (del acto administrativo por una decisión jurisdiccional) no será generalmente posible en los supuestos de potestades discrecionales, habiendo un núcleo último de oportunidad alli donde son posibles varias soluciones igualmente justas en el que no cabe sustituir la decisión administrativa por una decisión judicial.

Tal jurisprudencia no ha sido vulnerada por la sentencia recurrida puesto que en el presente supuesto, no caben varias soluciones justas al problema planteado, ya que la resolución a tomar, en la interpretación del artículo 138 tantas veces repetido, encierra conceptos jurídicos indeterminados de indudable naturaleza reglada, lo que excluye toda discrecionalidad-sentencias del TS de 8 de noviembre de 1990 y 12 de abril de 1996-, aunque en su aplicación haya de reconocerse un cierto margen de apreciación.

\footnotetext{
${ }^{67}$ Puede verse a tal efecto la STS de 16 de junio de 1993 (Aranzadi RJ 1994\4884).

${ }^{68}$ En igual sentido la STS de 17 de octubre de 1995 (Aranzadi RJ 199517512).
} 
Precisamente, la naturaleza reglada del precepto no admite más que una solución conforme a Derecho, la de si el proyecto de urbanización, integra o no una agresión al medio ambiente, lo que ha de ser el resultado de la valoración de las circunstancias concurrentes.

No obstante, la interpretación de los conceptos citados no es estática y así lo recuerda la propia sentencia de 21 de noviembre de 2000, cuando establece en relación con la aplicación del artículo 138 b) del RD Leg 1/1992, de 26 de noviembre, que: Desde luego, tales circunstancias o conceptos, han de ser interpretados, de modo muy especial, conforme a la realidad social del tiempo en que han de ser aplicados —artículo 3 del Código Civil-, siendo de notar que tal realidad social en estos momentos, refleja una muy intensa preocupación en conservar y mantener las perspectivas naturales y la armonía del medio ambiente, respecto de las construcciones y recuerdos históricos legados por nuestros antepasados.

En este sentido la STS de 24 de Octubre de 1990, ya citada, señala que para su interpretación:

se abre en dos diferentes puntos de vista, uno, por el efecto producido, consistente en la limitación del campo visual para contemplar las bellezas naturales, la rotura de la armonía del paisaje o la desfiguración de la perspectiva propia del mismo, y otro, por los elementos de hecho susceptibles de causarlo, constituidos por la situación, masa y altura de los edificios, muros y cierres o la instalación de otros igualmente eficaces a tales fines.

Por lo que para cada caso concreto es preciso dilucidar:

en primer lugar, si se da el supuesto previsto en la norma para que la misma resulte aplicable, es decir, la existencia de un paisaje rural abierto y natural digno de protección por su belleza en el espacio en que se ubica la finca que el actor pretende cerrar, y en segundo término, si las características del cerramiento proyectado por éste son plenamente eficaces para producir los efectos de limitar el campo visual para contemplar las bellezas naturales, romper la armonía del paisaje o desfigurar la perspectiva propia del mismo.

Esto obliga, como señala la sentencia, en primer lugar a hacer constar en el expediente administrativo los datos de los que sea factible deducir que el entorno del lugar en que se encuentra la finca del recurrente constituya un paisaje rural abierto y natural que por su belleza se haga acreedor de una especial protección

Y además una cumplida acreditación de que la construcción rompa esa armonía, como así señala la STS de 31 de diciembre de 1988 (Aranzadi RJ $1988 \backslash 10293)^{69}$.

${ }^{69}$ La sentencia señala que: Así las cosas, ha de entenderse, por una parte, que la edificación para 
En consecuencia, la Sentencia al verificar que en el expediente no existen datos al respecto que hubieran podido determinar la recta formación de la voluntad administrativa. Y es más, es que ésta ni siquiera decidió nada en consideración a la belleza de la zona. Acuerda la anulación del actuaciones a fin de que con un estudio detallado del monte y de las edificaciones pretendidas y con audiencia del interesado la Corporación adopte la decisión adecuada a Derecho.

En consecuencia, el principio de objetividad y la necesidad de acreditar las razones de hecho que justifican la aplicación del artículo exigen, conforme indica la STS de 14 de noviembre de 1986 (Aranzadi RJ 198618082), que la restricción del derecho de edificar no pueda motivarse en criterios subjetivos de los miembros de la Corporación Municipal, que deben resolver atendiendo a elementos de juicio de carácter técnico o estético que se sustentan por dictámenes, o que dimanen del proyecto formulado por el solicitante y que se encuentren incorporados en el expediente.

Esta declaración es lógica consecuencia de la necesidad de que el control se base en los hechos determinantes de la aplicación de la norma pues, como señala una reiterada jurisprudencia, la revisión jurisdiccional de la actuación administrativa se extenderá, en primer lugar, a la verificación de la realidad de los hechos, para, en segundo término, valorar si la decisión planificadora discrecional guarda coherencia lógica con aquéllos, de suerte que cuando sea clara la incongruencia o discordancia de la solución elegida con la realidad, que es su presupuesto inexorable, tal decisión resultará viciada por infringir el ordenamiento jurídico y más concretamente el principio de interdicción de la arbitrariedad de los poderes públicos - art. 9., 3 de la Constitución-, que en lo que ahora importa, aspira a evitar que se traspasen los límites racionales de la discrecionalidad y se convierta ésta en causa de decisiones desprovistas de justificación fáctica alguna ${ }^{70}$, pero esta situación simultáneamente exige que el término de comparación de la realidad con la norma se base en un criterio objetivo y no en la mera decisión del órgano municipal, lo que indudablemente, en el caso del paisaje, impide justificar una decisión relativa al mismo en el

\footnotetext{
la que se pretende la licencia ofrece un cierto «riesgo» para la armonía del paisaje, sin que, por otra, existan datos suficientes para poder afirmar que efectivamente vaya a «romper» aquella armonía; para decidir esta cuestión sería preciso un estudio completo de las características del monte, su belleza y su perspectiva en relación con el aspecto, altura y configuración de la edificación pretendida. Son estos los datos que ahora faltan planteándose la duda de si lo procedente ha de ser una anulación de actuaciones o si por el contrario podría resolverse el recurso mediante pruebas acordadas para mejor proveer.
}

${ }^{70}$ STS de 1 de diciembre de 1986 (Aranzadi RJ 1987\417). 
mero carácter de representación democrático de la Corporación que aprueba el Planeamiento.

El concepto de paisaje, como se ha venido indicado a lo largo de esta exposición, plantea claros problemas en su determinación y valoración, en este sentido debe tenerse en cuenta dos criterios de interpretación de forma necesario, el derivado de las acuerdos y convenios internacionales y el de la normativa interna.

En relación con el primero de ellos es preciso traer a colación la Convención Europea del Paisaje adoptado por el Consejo de Europa y aprobada el 19 de julio de 2000 por el Consejo de Ministros del Consejo de Europa, y que es conocido como la Convención de Florencia ${ }^{71}$, encontrándose la misma suscrita por el Estado español, para la misma puede definirse el paisaje como «cualquier parte del territorio, tal como es percibida por las poblaciones, cuyo carácter resulta de la acción de factores naturales y/o humanos y de sus interrelaciones» ${ }^{72}$ siendo aplicable dicha Convención tanto a los espacios naturales como a los rurales, urbanos y periurbanos, incluidos los espacios terrestres, las aguas interiores y marítimas y concierne tanto a los paisajes que pueden ser considerados notables, como a los paisajes cotidianos y a los paisajes degradados, debiendo destacar que la misma remite a la determinación por cada Estado de los órganos competentes para su desarrollo de conformidad con sus principios constitucionales y a su organización administrativa, respetando el principio de subsi-

\footnotetext{
${ }^{71}$ Puede verse una referencia a otros acuerdos internacionales y normas nacionales sobre protección del paisaje en Arturo GonZÁLEZ QuinZA, «La protección del paisaje frente a las agresiones producidas por la instalación del servicio publico telefónico» en Revista de Derecho Urbanístico cit., edición electrónica.

${ }^{72}$ La Convención Europea del Paisaje contiene además las siguientes definiciones: «Política del paisaje» designa la formulación por las autoridades públicas competentes de los principios generales, las estrategias y las orientaciones que permiten adoptar medidas particulares para la protección, la gestión y la ordenación del paisaje;
}

«Objetivos de calidad paisajística» designa la formulación por las autoridades públicas competentes, para un determinado paisaje, de las aspiraciones de las poblaciones en cuanto se refiere a las características paisajísticas del entorno en el que viven;

«Protección de los paisajes» comprende las actuaciones para la conservación y el mantenimiento de los aspectos significativos o característicos de un paisaje, justificados por su valor patrimonial que proviene de su particular configuración natural y/o de la intervención humana;

«Gestión de los paisajes» comprende las actuaciones dirigidas, en la perspectiva del desarrollo sostenible, al mantenimiento del paisaje con el fin de guiar y armonizar las transformaciones inducidas en él por la evolución social, económica y ambiental;

«Ordenación de los paisajes» comprende las actuaciones que presentan un carácter prospectivo particularmente acentuado y encaminadas a la mejora, la restauración o la creación de paisajes. 
diariedad y tomando en consideración la Carta Europea de la Autonomía Local.

La Convención Europea sobre el paisaje obliga, entre otras determinaciones, a integrar el paisaje dentro de las políticas de ordenación del territorio y urbanismo, comprometiéndose los firmantes a desarrollar programas de formación y educación a identificar y calificar sus paisajes a obtener objetivos de calidad del paisaje y a la aplicación de políticas con destino a la protección, gestión y ordenación del mismo ${ }^{73}$.

En el ámbito de la normativa estatal se encuentran claras referencias al paisaje en diversas normas como son la Ley 4/1989, de 27 de marzo, de Conservación de los Espacios Naturales y de la Flora y Fauna Silvestre, el RD 1997/1995, de 7 de diciembre, que desarrolla la Directiva Comunitaria 92/43/CEE relativa a la conservación de los hábitats naturales y de la fauna y flora silvestres, el RDLEg 1302/1986, de 28 de junio, de evaluación de impacto ambiental, normativas sectoriales como la Ley de Aguas, Costas, Carreteras etc., pudiendo citar en la normativa autonómica tanto a la Ley $2 / 2001$, de 25 de junio, de Ordenación Territorial y Régimen Urbanístico del Suelo de Cantabria, como a la Ley 4/2000, de 13 de noviembre, de Modernización y Desarrollo Agrario, la Ley 5/1999, de 24 de marzo, de Ordenación del Turismo de Cantabria, la Ley 11/1998, de 13 de octubre, de Patrimonio Cultural de Cantabria, la Ley 5/1996, de 17 de diciembre, de Carreteras de Cantabria, y la Ley 8/1993, de 18 de noviembre, del Plan de Gestión de Residuos Sólidos Urbanos de Cantabria, si bien tienen en ellos una marcada perspectiva excepcional.

De estas Convenciones y normativa no es posible, salvo en los casos expresamente previstos en los mismas como son los paisajes protegidos de la Ley 4/1989 pero que se limitan a aquellos lugares concretos del medio natural que por sus valores estéticos y culturales sean merecedores de una protección especial o los que puedan derivarse de los Lugares Culturales de la Ley de Cantabria 11/1998, establecer reglas generales aplicables de forma objetiva, lo cual exigirá al aplicador de la norma una especial labor de integración y justificación ${ }^{74}$.

\footnotetext{
${ }^{73}$ En este mismo sentido puede también señalarse como antecedentes internacionales a la «Convención para la Protección del Patrimonio Cultural y Mundial» aprobada por la UNESCO en 1972.

${ }^{74}$ En cuanto a la importancia que la valoración pericial de la apreciación del paisaje tiene en las posibles impugnaciones los acuerdos municipales puede verse el estudio detallado y la jurisprudencia recogida por Enrique SÁNCHEZ GoYANES, «Urbanismo y protección del paisaje. Las (mal) llamadas y (peor entendidas) normas de aplicación directa...», páginas 105 y ss.
} 
Las dificultades apuntadas hacen que la LOTRUSC haga una expresa remisión al Planeamiento como elemento necesario de concreción y seguridad jurídica, el cual, como hemos señalado, tiene como misión limitar la zona de incertidumbre pero en ningún caso supone la adopción de decisiones discrecionales.

Por último destacar que las modificaciones introducidas en el artículo 34 en relación con el 138 b) del RD Leg 1/1992, de 26 de junio tiene por finalidad incidir en la necesidad de preservar no sólo el paisaje rural o marítimo, sino también las perspectivas de los propios núcleos de población que así puedan plantearse, estimando el paisaje no exclusivamente como una observación exclusivamente de los espacios naturales sino también de aquellas obras humanas que por sus características han quedado integradas en el entorno como un elemento propio y característico del mismo, en los términos recogidos en la Convención de Florencia, añadiendo igualmente como elemento clarificador que dentro de los elementos productores de afección se incluye la publicidad estática que por sus dimensiones, localización o colorido no cumpla las anteriores prescripciones, incluyendo a estos efectos en el concepto de publicidad los carteles anunciadores de locales y establecimientos mercantiles, prescripción en parte innecesaria si se tiene en cuenta el sometimiento de estos carteles a licencia, conforme al artículo 183 de la Ley cántabra, por lo que su inclusión en el apartado podía entenderse englobada dentro del apartado de «otros elementos» que recoge el artículo 138 b) del RD Leg 1/1992.

El apartado segundo del artículo 34 establece que

En los conjuntos urbanos a los que se refiere el apartado anterior, la tipología de las construcciones habrá de ser, además, congruente con las características del entorno. Los materiales empleados para la renovación y acabado de fachadas, cubiertas y cierres de parcelas habrán de armonizar con el lugar en que vayan a emplazarse. Los mismos requisitos serán de aplicación a las obras de rehabilitación, modernización o conservación de los inmuebles ya existentes.

Nos encontramos ante una típica norma de aplicación directa cuya diferencia con respecto al artículo 33 anterior, radica en que en el presente caso su aplicación no se limita a los Bienes inventariados o Catalogados, ya sea en aplicación de la legislación del Patrimonio Cultural o en el Catalogo del Plan, sino a todos aquellos inmuebles ubicados en conjuntos urbanos que puedan considerarse históricos, típicos o tradicionales, se encuentren protegidos o no, y sobre los que se realicen nuevas construcciones o actuaciones sobre las existentes y su finalidad, en el presente caso, no es solo la armonización con las edificaciones colindantes o el conjunto inmo- 
biliario, circunstancias que se podía derivar del artículo 32 de la LOTRUS, sino la protección del paisaje.

El artículo pretende impedir la realización de construcciones fuera del contexto de la arquitectura tradicional en lugares inadecuados, así, no es difícil encontrarnos casas prefabricadas de madera en conjuntos urbanos caracterizados por el uso de la piedra, los cuales pueden desvirtuar de forma clara a todo el conjunto y, en todo caso, dicho apartado es de aplicación a aquellos conjuntos urbanos no incluidos en una clasificación de protección del patrimonio cultural o catalogados, ya que en caso contrario supondría una reiteración del artículo 33.

Su aplicación no requiere de la existencia de Plan o Norma por lo que puede predicarse el carácter de norma directa de aplicación inmediata, en todo caso vuelve a surgir en este apartado la necesidad de concretar los conceptos jurídicos indeterminados que el precepto hace gala y del que exclusivamente la casuística de la actuación y la motivación de los criterios que determinan la concesión o denegación de la actuación permitirán su correcta aplicación.

Obviamente, el mayor o menor grado de conservación del conjunto urbano sobre el que se vaya a actuar exigirá una mayor o menor observancia de las formas y materiales a emplear en relación con los tradicionales de la zona, en todo caso su aplicación exigiría la necesaria fijación y acreditación de cuales son los elementos que constituyen los acabados de fachadas, cubiertas y cierres, exclusivos elementos a los que se circunscribe la norma, a fin de acreditar los motivos de la denegación, por lo que en este apartado y en defecto de planeamiento municipal las Normas Urbanísticas Regionales están llamadas a cumplir una función determinante.

Por último, el apartado tercero del artículo 34 de la LOTRUSC recoge la obligación de que los instrumentos de planeamiento concreten, pormenoricen y definan los criterios anteriores, ya que corresponde a los planes de ordenación la determinación a que debe sujetarse el destino y uso de los solares, a fin de que el paisaje no se vea lesionado, lográndose así el objetivo de llevar claridad a una materia en la que, sin esa precisión normativa, pueden involucrarse peligrosos subjetivismos, claridad que redunda en favor de la Administración,que sabrá hasta dónde puede llegar en su función interventora a la hora de proteger el paisaje y que le permitirá acomodar (sic) los planteamientos económicos vinculados al aprovechamiento del suelo y a los límites que dicho paisaje imponga, facilitando igualmente el control jurisdiccional de los actos administrativos que se reputen contrarios a Derecho, al disponer los Tribunales de los elementos 
con que poder examinar las circunstancias reales que han de calificarse y con los que poder hallar el sentido jurídico preciso que la norma ha asignado al concepto jurídico indeterminado que es «la protección del paisa$j e \gg{ }^{75}$.

La LOTRUSC, consciente de la necesidad de que el Planeamiento contribuya a la seguridad jurídica de la actividad urbanística, exige que éste defina los elementos de protección recogidos en este articulado, no obstante, el problema práctico que se plantea es cuál es el mecanismo adecuado a través de los cuales éstos se efectúan y cuales son las consecuencias de que el Planeamiento los recoja.

La protección del paisaje y sus perspectivas no es un elemento tradicional de análisis exhaustivo en el urbanismo más preocupado por otras cuestiones atinentes al desarrollo urbano y que en cierta medida se encuentra diferido a la Evaluación de Impacto Ambiental, aunque no quiere decirse que el mismo se encuentre olvidado, no obstante, su plasmación en el Plan requiere con carácter previo de:

a. Determinación de cuales son aquellos elementos paisajísticos a proteger.

b. Cuáles son los lugares de perspectiva a proteger.

c. Cual es el concreto instrumento en el que debe recogerse dicho análisis.

Un breve análisis de la LOTRUSC nos devela claramente que la protección del paisaje se confía en particular a los Planes Especiales, ya sean éstos los recogidos al artículo 59,1, es decir, los formulados por la Comunidad Autónoma en desarrollo directo de las previsiones contenidas en el Plan Regional de Ordenación Territorial y en las Normas Urbanísticas Regionales o, en su caso, en los Planes y Normas Comarcales, o aquellos que pueden formular los Ayuntamientos en ausencia de Plan Regional de Ordenación Territorial, Normas Urbanísticas Regionales y de Plan General de Ordenación Urbana, si bien su operatividad se circunscribirá exclusivamente al ámbito municipal, curiosamente ni el artículo 44 ni el 45 de la LOTRUSC, relativos a los contenidos necesarios y optativos de los Planes Generales, hacen mención expresa al paisaje, aunque sí a la protección de los elementos arquitectónicos o naturales, no obstante lo cual en caso de existencia de Plan General debe ser este el que establezca cuales son estos elementos dignos de protección.

${ }^{75}$ STSJ de Cantabria de 14 de septiembre de 1998 (Aranzadi RJCA 199813949). 
A mi parecer, los criterios de protección paisajística deben contenerse en la Memoria del Plan, pues su aplicación determinará indudablemente un concreto régimen jurídico de utilización y aprovechamiento del suelo, y en consecuencia requiere su justificación, y solo exclusivamente en aquellos espacios en los que concurran circunstancias objetivas de necesaria protección, por concurrir en el mismo criterios paisajísticos específicos, debería el Plan aportar un estudio paisajístico de las posibles alternativas existentes y de justificación de la decisión adoptada.

En todo caso, es indudable que en la lógica del carácter prevalente que la LOTRUSC otorga a las Normas de Aplicación Directa ni siquiera la inclusión en el Plan de estos conceptos asegura su perdurabilidad y la imposibilidad de impugnación de una licencia en base a incumplimiento de los mismos y, en consecuencia, si se acredita la existencia de un paisaje de necesaria protección es indudable que el Plan sucumbirá a la reclamación. No obstante, la inclusión en la documentación de éste de los criterios paisajísticos adoptados garantiza una cierta objetividad en la decisión puesto que en su tramitación habrán tenido intervención los organismos sectoriales a los que esta encomendado la defensa de aquellos valores $^{76}$, y en todo caso exigiría por parte del reclamante una prueba clara y determinante por una parte de la existencia de un paisaje singular de necesaria protección, en segundo lugar, de la afectación a la misma de la construcción y en tercer lugar de que la decisión contenida en el Plan General vulnera el fin exigido a la norma relativo a la protección del paisaje por cuanto la decisión plasmada en la misma no garantiza su consecución.

En suma, cuando el planificador se enfrenta con esta situación debe necesariamente efectuar en primer lugar una actividad de concreción, es decir, debe, a la vista de los conceptos jurídicos indeterminados plasmados en la norma, concretar su existencia en el término municipal sobre el que se actúa, para posteriormente justificar, dentro de la zona de incertidumbre de estos conceptos, las posibles decisiones a adoptar para la protección del paisaje y de los conjuntos urbanos, en su aplicación no hay ningún ámbito para la aplicación de la discrecionalidad administrativa pues la Administración tiene predeterminados los hechos determinantes y el fin de la norma y por otra parte la zona de incertidumbre del concepto jurídico es muy limitada, no siendo ni siquiera libre para la adopción de la aplicación o no de la norma.

\footnotetext{
${ }^{76}$ Enrique SÁnchez Goyanes, «Urbanismo y protección del paisaje. Las (mal) llamadas y (peor entendidas) normas de aplicación directa...», op. cit., página 84.
} 


\section{NORMAS DE APLICACIÓN DIRECTA Y AUTONOMÍA MUNICIPAL}

Las Normas de Aplicación Directa recogidas en la LOTRUSC plantean necesariamente un problema añadido al relativo al control de la discrecionalidad administrativa o de aplicación de los conceptos jurídicos indeterminados, como es el relativo a la autonomía municipal en el ejercicio de su potestad de planificación.

No se plantea por tanto, en este caso, la necesidad de control de la discrecionalidad administrativa, ni por supuesto la de los conceptos jurídicos indeterminados y en su caso la aplicación que de las mismas pudieran efectuarse por los órganos jurisdiccionales, ya que obviamente así lo permite la Constitución, en tal medida la existencia de tal control y las técnicas bajo las que la mismas se desarrollan no son susceptibles de crítica en este momento.

Ya se ha señalado anteriormente la configuración de la potestad de planeamiento como una potestad con una gran carga de discrecionalidad, pero a la vez su carácter derivado de la Ley y su sujeción a los preceptos de la misma y la necesaria participación de los Entes locales, pues como se ha indicado la distribución de competencias en la aprobación de los instrumentos de planeamiento entre las Comunidades Autónomas y las Corporaciones Locales en materia de urbanismo no puede obviar que el urbanismo hace referencia a una magnitud local, al espacio de convivencia urbana, a la acción pública de regulación directa y precisa del uso del suelo, de modo que ni el legislador estatal ni el autonómico gozan de discrecionalidad para seleccionar la autoridad capacitada para elaborar y aprobar un Plan ${ }^{77}$.

Derivada de esta declaración es preciso señalar que la especial configuración de la Autonomía Municipal recogida en nuestra Constitución, sin un ámbito competencial específicamente protegido por la misma y cuya garantía institucional radica en la participación de los Entes Locales en los asuntos que afectan a la esfera de los intereses vecinales ${ }^{78}$, plantea nece-

\footnotetext{
77 Juan Manuel BANDRÉs SÁNCHEZ-CRUZAT, «El control de la legislación delegada en materia urbanística y el prencipio de autonomía local (Comentario al Auto del Tribunal Superior de Justicia de Cataluña de 6 de abril de 1993)», Revista de Estudios de la Administración Local y Autonómica, nº 263, julio-septiembre 1994, página 559.

${ }^{78}$ En cuanto a la garantía constitucional de la Autonomía Local puede verse Luciano PAREJo Alfonso, «La Autonomía Local», Revista de Estudios de la Administración Local y Autonómica, n 229 , enero-marzo 1986, página 39, igualmente Francisco Sosa Wagner, «La Autonomía
} 
sariamente la necesidad de analizar dos situaciones en orden a la posible vulneración de la misma: La primera de ellas se produce tras el reconocimiento de la potestad reglamentaria a los Entes Locales ${ }^{79}$ que se vería afectada por la actuación del legislador en orden a la limitación de su Autonomía mediante la creación de una legislación caracterizada por una densidad reguladora que predetermine, de hecho y de forma excluyente, los posibles desarrollos de la misma ${ }^{80}$, aunque favorezca obviamente el control de la discrecionalidad municipal, y la segunda en relación con el control que de su actividad puedan efectuar los órganos de otras Administraciones, en este caso concreto de la Comunidad Autónoma en cuanto tiene atribuida competencias en materia de coordinación en este sector del ordenamiento.

En relación con el primer apartado el análisis ha de partir de la pregunta de si el legislador sectorial ha respetado el ámbito de participación municipal o a introducido límites al mismo, de tal manera que impide a la Entidad Local el ejercicio de su autonomía constitucionalmente garantizada, sustrayendo a los Municipio una competencia que es de marcador carácter local ${ }^{81}$, que no olvidemos se plasma en este caso en el ámbito de discrecionalidad que el mismo dispone para elegir su concreto modelo urbanístico.

Debe partirse necesariamente de la Carta Europea de la Autonomía Local que manifiesta que por autonomía local se entiende el derecho y la capacidad efectiva de las Entidades Locales de ordenar y gestionar una parte de los asuntos públicos, en el marco de la ley, bajo su propia responsabilidad y en beneficio de sus habitantes, señalado a tal efecto en su artículo 4 que:

Las competencias encomendadas a las Entidades Locales deben ser normalmente plenas y completas. No pueden ser puestas en tela de juicio ni limitadas por otra autoridad central o regional, más que dentro del ámbito de la Ley.

\footnotetext{
Local», Revista de Estudios de la Administración Local y Autonómica, nº 241, enero-marzo 1989, página 18, sobre la configuración de una «garantía constitucional de la autonomía local» y la limitación del concepto de «garantía institucional» puede verse Javier García RoCA, «El concepto de autonomia local según el bloque de constitucionalidad», Revista de Estudios de la Administración Local y Autonómica, $\mathrm{n}^{\circ}$ 282, enero-abril 2000, página 35.

${ }^{79}$ Sobre potestad reglamentaria y autonomía local, Luciano Parejo Alfonso, «La Autonomía Local» cit., página 33, Santiago A. Bello Paredes, Las ordenanzas locales en el vigente Derecho español. Alcance y articulación con la normativa estatal y autonómica Madrid, INAP-Universidad de Burgos, 2002, páginas 115-119.

${ }^{80}$ A la relación existente entre densidad normativa y control de la discrecionalidad se ha referido M. BACIGALUPO, La discrecionalidad administrativa, cit., página 222 y ss.

${ }^{81}$ Javier GARCíA RocA, «El concepto de autonomia local», cit., páginas 44 y 61.
} 
En este sentido puede afirmarse, siguiendo a la doctrina, que los municipios deben ejercer la función de ordenación, incluida dentro de la competencia sobre urbanismo, desde la consideración de esta función como propia, exclusiva y decisoria ${ }^{82}$, consecuentemente se ha señalado que la potestad normativa en materia urbanística no deriva de una atribución legal, sino que es aplicación en un ámbito competencial municipal de la normativa general que deriva directamente de la autonomía municipal constitucionalmente garantizada, por tanto, los planes de urbanismo no ejecutan la legislación urbanística, sino que suponen la plasmación de la competencia municipal sobre ordenación urbanística, de ahí «la imposibilidad de una ley autonómica de regular exhaustivamente el uso del suelo no se basa en una cuestión de dificultad puramente práctica -la concreción extrema que esta operación requeriría - sino que tiene su fundamento en la obligación constitucional del legislador urbanístico de respetar un ámbito discrecional municipal derivado de la autonomía municipal, en el ejercicio de la competencia propia de ordenación urbanística» ${ }^{83}$.

No obstante, lo cierto es que la autonomía municipal ha sido interpretada con un carácter limitado en nuestro Derecho y que en este sentido el Tribunal Constitucional ha recogido de forma continuado tal característica, así en la STC de 5 de julio de 2001, señala que:

Sobre el concepto y el contenido de la autonomía local y el ámbito competencial que han de respetar, en relación con ella, los legisladores estatal y autonómicos, tempranamente dijimos que la autonomía local «hace referencia a la distribución territorial del poder del Estado en el sentido amplio del término, y debe ser entendida como un derecho de la comunidad local a participar, a través de órganos propios, en el gobierno y administración de cuantos asuntos le atañen, constituyendo en todo caso un poder limitado que no puede oponerse al principio de unidad estatal» (SSTC 4/1981, de 2 de febrero, FJ 3, y 32/1981, de 28 de julio, FJ 3, doctrina posteriormente reiterada, entre otras, por las SSTC 27/1987, de 27 de febrero, FJ 2, 170/1989, de 19 de octubre, FJ 9, o 109/1998, de 21 de mayo, FJ 2).

Por otra parte, como la misma Sentencia se encarga de señalar en relación con la autonomía municipal, su configuración institucional concreta se defiere al legislador ordinario, al que no se fija más límite que el del reducto indisponible o núcleo esencial de la institución que la Constitución garantiza, de modo que como ha venido señalado el Tribunal «la garantía institucional de la autonomía local no asegura un contenido concreto ni un determinado ámbito competencial, "sino la preservación de una institución en términos reconocibles para la imagen que de la misma

\footnotetext{
82 Julio Ponce SolÉ, Discrecionalidad urbanística, ob. cit., página 62.

83 Julio Ponce Solé, Discrecionalidad urbanística, ob. cit., páginas 93 y 95.
} 
tiene la conciencia social en cada tiempo y lugar", de suerte que solamente podrá reputarse desconocida dicha garantía "cuando la institución es limitada, de tal modo que se la priva prácticamente de sus posibilidades de existencia real como institución para convertirse en un simple nombre" (STC 32/1981, FJ 3)».

Por tanto el Tribunal Constitucional como medio para entender la garantía institucional señala que:

Sólo aquellos extremos de la LBRL que puedan ser cabalmente enraizados de forma directa en los arts. 137, 140 y 141 CE, de cuyo contenido no representen más que exteriorizaciones o manifestaciones, forman parte del contenido de la autonomía local constitucionalmente garantizada, mientras que los que se refieran a aspectos secundarios o no expresivos de ese núcleo esencial en el que consiste la garantía institucional, que son mayoría en el seno de la LBRL y que se incardinan, desde el punto de vista competencial, en el art. 149.1.18 CE, tienen una distinta naturaleza desde el punto de vista constitucional y ordinamental.

Partiendo de este concepto como núcleo esencial de la garantía institucional de los Entes Locales y en el ámbito del urbanismo, que el Tribunal viene a señalar expresamente como un asunto de interés de los municipios, llega a la conclusión específica de que: cabe desde este momento afirmar que la Administración territorial a la que el constituyente encomendó la competencia normativa en urbanismo (las Comunidades Autónomas, según el art. 148.1.3 CE, pero también el Estado, cuando resulte habilitado al efecto por otros títulos competenciales) está legitimada para regular de diversas maneras la actividad urbanística, y para otorgar en ella a los entes locales, y singularmente a los Municipios, una mayor o menor presencia y participación en los distintos ámbitos en los cuales tradicionalmente se divide el urbanismo (planeamiento, gestión de los planes y disciplina), siempre que respete ese núcleo mínimo identificable de facultades, competencias y atribuciones (al menos en el plano de la ejecución o gestión urbanística) que hará que dichos entes locales sean reconocibles por los ciudadanos como una instancia de toma de decisiones autónoma e individualizada.

En consecuencia, para el Tribunal Constitucional la garantía institucional de las Entidades Locales no abarca el contenido de la potestad de planeamiento que necesariamente debe moverse dentro de los límites que la Ley le ha establecido, sin que en este sentido la predeterminación de las soluciones que esta contengan supongan, a priori, vulneración de la Autonomía municipal constitucionalmente garantizada, por lo que obviamente se impide, al menos como requisito exclusivo exigible la legislador, el respeto a un ámbito de decisión exclusivamente propio del Ayuntamiento que 
le permitiese el establecimiento de un modelo propio municipal en cuanto a la ordenación de su territorio.

No obstante, pese al concepto limitado que nuestro Tribunal Constitucional manifiesta de la autonomía municipal, prácticamente constreñido al respeto a la garantía institucional que garantiza la existencia de los Entes Locales, es indudable que es precisa la participación municipal en la planificación, pues el urbanismo es una materia ligada al territorio, y cuyo origen tenía por objeto «crear ciudad». Ello exige cuando menos una intervención del municipio en el planeamiento, que no puede en ningún caso obviarse cuando afecte intereses meramente locales, teniendo en cuenta además que uno de los principios que debe regir toda sociedad democrática, y hacia el cual debe orientarse el legislador en cumplimiento del artículo 1.1 de la CE, es el de asegurar la máxima proximidad de los órganos de decisión a los ciudadanos, más en una materia como ésta que les afecta tan directamente, a través, en su caso, de los órganos democráticamente elegidos para el gobierno municipal ${ }^{84}$.

En consecuencia, los municipios deben moverse dentro del ámbito que la Ley les dibuja, sin que estas predeterminaciones puedan considerarse vulneración de su autonomía, aunque ciertamente si limitativas de la planificación como ámbito de decisión propio de los Ayuntamientos, en este sentido no podría argumentarse vulneración constitucional a las Normas de Aplicación Directa en cuanto no suponen un menoscabo del contenido mínimo e indisponible de la autonomía municipal, pero si ponen de manifiesto el mayor o menor respeto que a la autonomía municipal tiene el legislador autonómico.

Cuestión distinta se plantea en relación con la plasmación en el ámbito del planeamiento de las Normas de Aplicación Directa por parte de las Entidades Locales, pues aquí nos encontramos ya en el ámbito de la ejecución de la Ley en la cual la autonomía municipal tiene una perspectiva distinta.

Partiendo de este criterio se encuentra plenamente asentada la doctrina de que en base al principio constitucional de autonomía municipal la extensión del control de la Comunidad Autónoma en el momento de la aprobación definitiva del planeamiento queda reducida a los aspectos reglados del Plan, respecto a los cuales existe el control pleno de la Comunidad Autónoma, y a aquellos aspectos discrecionales que inciden en

${ }^{84}$ STS Justicia de Cataluña de 18 de febrero de 1997 (Aranzadi RJ 1997\787). 
materias de interés supramunicipal y comunitario, al entenderse siempre predominante éste sobre el puramente local o municipal ${ }^{85}$.

En consecuencia, la Comunidad Autónoma debe necesariamente, con carácter previo, analizar cuál es el interés recogido en el Planeamiento y en consecuencia limitar su actuación a las de carácter supramunicipal ${ }^{86} \mathrm{o}$ a la aplicación de un control de legalidad, lo que impide la adopción de decisiones discrecionales sobre intereses locales, tal como por ejemplo se recoge en la sentencia del Tribunal Supremo de 16 de octubre de 2001 (BDB TS 31702/2002), en la que se debate si una Comisión Provincial de Urbanismo, al proceder a la aprobación definitiva de la modificación puntual de las Normas Urbanísticas de un municipio, puede variar las condiciones de edificabilidad de un área en cuanto a su altura tal como se había determinado por el Ayuntamiento en la aprobación inicial y provisional.

En la sentencia recurrida ante el Tribunal Suprermo, se llega a la conclusión que la Comisión Provincial de Urbanismo en la aprobación definitiva de la modificación puntual de las Normas Subsidiarias había ejercido un control de estricta legalidad, respecto de la aprobación inicial y provisional realizada por el Ayuntamiento de Benacazón, por la falta de coherencia de la modificación municipal con las determinaciones de las Normas Subsidiarias, tanto respecto a alturas de edificaciones, volúmenes y conservación del entorno paisajístico, no obstante el Tribunal Supremo indica que:

la naturaleza y finalidad del «ius variandi» de la Administración municipal, precisamente radica en modificar el planeamiento vigente, para acomodarlo a las exigencias cambiantes de los intereses públicos, variando las determinaciones de ese planeamiento, por lo que, en principio, no parece lógico, calificar de falta de coherencia de la modificación puntual de las Normas Subsidiarias, con las determinaciones de las mismas, al ser su cambio, el presupuesto necesario del contenido del «ius variandi» municipal.

En consecuencia, siendo la altura y volúmenes el contenido mas típico del ius variandi y en razón de que no la existencia de intereses supramunicipales que concurrieran en este caso el Tribunal Supremo entendió conforme los acuerdos municipales en este apartado, sin embargo para el Tribunal es más problemático y controvertido el tema de la protección del medio ambiente entre el que ha de incluirse la tutela del paisaje, y reflejado en el artículo 45 de la Constitución en base y referencia «al derecho de

\footnotetext{
${ }^{85}$ Por todas ellas puede verse la STS de 27 de enero de 2001 (BDB TS 3087/2001).

${ }^{86}$ En este mismo sentido Javier GARCÍA RoCA, «El concepto de autonomia local», cit., página 57.
} 
disfrutar un medio ambiente adecuado para el desarrollo de la persona», señalando a tal efecto que:

No puede caber duda que la notoria afectación a la contemplación del paisaje serrano, derivado de la construcción de un edificio, y su aprobación por el órgano municipal, constituye, si, un acto discrecional o de oportunidad, pero de indiscutibles repercusiones en los intereses supramunicipales, que pueden y deben ser controlados en el acto de aprobación definitiva del planeamiento por la Comunidad Autónoma, con arreglo a la doctrina anteexpuesta.

Más en el supuesto, objeto de esta litis, y conforme al resultado de la prueba pericial practicada, en relación con las demás, y con el propio proyecto aprobado por la Administración Autonómica, que redujo a dos alturas, el proyecto aprobado por el municipio, parece desprenderse que dada la ubicación del inmueble «Andalusi Park Hotel» en lugar alejado del centro urbano y en un enclave de carreteras, la altura del mismo inicialmente aprobada, no implica un deterioro apreciable del medio ambiente en su incidencia paisajistica, por lo que tampoco puede ser considerado tal aspecto como propiamente constitutivo de un interés supralocal, habiendo pues de ser mantenida la determinación municipal reflejada en la aprobación inicial y provisional de la modificación de las Normas Subsidiarias.

En consecuencia, los valores paisajísticos y ambientales no pueden atribuirse como de la exclusiva competencia de una Administración, por lo que dado el carácter bifásico de muchas de los procedimientos establecidos en el ámbito urbanístico, es preciso tener en cuenta la necesaria participación de la Comunidad Autónoma, como en tal sentido es recogido por la STSJ de Cantabria de 28 de abril de 2001 (BDB TSJ Cantabria $20901 / 2001)^{87}$, la cual establece entre sus considerandos los pronunciamientos que en este mismo sentido ha efectuado del Tribunal Supremo como la de 8 de marzo de 1999, cuando afirma que:

«En segundo lugar, afirmar que la competencia para velar por los valores paisajísticos, ecológicos, históricos y artísticos es competencia exclusiva de autoridades municipales del lugar en que radican los valores susceptibles de protección, es claramente erróneo. Efectivamente, los valores mencionados radican en un punto del espacio, pero el interés por su conservación y mantenimiento no lo ostentan, de

${ }^{87}$ Esta sentencia señala que:

En efecto, si la preservación y defensa del medio ambiente ha sido encomendado por la Constitución a todos los poderes públicos, que deben velar por el cumplimiento de dicho objetivo, y el art. 138 supone la plasmación en el ámbito urbanístico de este principio fundamental, su observancia y aplicación, que como se ha dicho es directa, sin necesidad de determinación específica en el planeamiento que lo desarrolle e incumbe no sólo a la Administración municipal, en cuanto otorgante de licencias de obra, sino igualmente a la Administración autonómica, a quien se encomiendan por la Ley del Suelo el control de las edificaciones en suelo no urbanizable, de tal modo que los Acuerdos de la misma deberán velar por la protección del paisaje, en cuanto valor primordial del medio rural, pudiendo limitarse las construcciones que pudieran suponer un atentado contra el mismo, máxime cuando dicha belleza natural del entorno donde se pretende ubicar la vivienda litigiosa ya ha comenzado a degradarse por la acción del hombre. 
modo exclusivo, las autoridades del lugar en que los bienes radican. Contrariamente, todos los que tienen legalmente atribuidas labores de vigilancia y control para la tutela de esos valores han de tener alguna competencia a efectos de decidir sobre las acciones que tengan incidencia sobre los valores protegidos.»

No obstante, esa competencia no es de ejercicio indiferente por una $\mathrm{u}$ otra, sino que la misma debe necesariamente acomodarse al criterio del interés protegido y en este sentido no cabe un control basado en un mero control discrecional o arbitrario, no existe avocación de competencias sino ejercicio de competencias propias, por tanto la intervención de la Comunidad Autónoma se justifica en aras de preservar el principio de seguridad jurídica, en la actuación de intereses supralocales perceptibles, por la conexión de las determinaciones del plan con un modelo territorial superior fijados en un instrumento de ordenación del territorio o por la salvaguarda de intereses públicos establecidos con precisión en la Ley urbanística, como la protección del paisaje o la defensa del medio ambiente ${ }^{88}$.

De ello se desprende que la Comunidad Autónoma debe necesariamente en esta materia romper la presunción de validez del acto municipal mediante los siguientes consideraciones:

a. Existencia de un interés supramunicipal acreditado.

b. Concreción del interés y fijación de los elementos que lo integran.

c. Consecuencias del interés protegido a la aplicación de la norma.

La garantía institucional exige en suma que las competencias de la Comunidad Autónoma tengan como base el interés supralocal, que debe ser concretado en cada caso pues las técnicas de limitación de la discrecionalidad, existencia de los hechos determinantes, interés público como fin perseguido y conceptos jurídicos indeterminados, no se encuentran excluidos en las relaciones interadministrativas, de lo que se infiere la necesidad de que las resoluciones limitadores de las potestades municipales se encuentran motivadas y justificadas adecuadamente en cuanto a los elementos que posibilitan su aplicación.

\section{CONCLUSIONES}

Las Normas de Aplicación Directa han tenido en nuestro ordenamiento su nacimiento con base en la necesidad de posibilitar el ejercicio de los

${ }^{88}$ STS Justicia de Cataluña de fecha 29 de junio de 2000 (Aranzadi RJCA 2000\1695). 
derechos dominicales en las situaciones de ausencia de planeamiento, y con la finalidad de establecer un ordenamiento mínimo que garantizase la coherencia de la actuación pretendida con el entorno dada la ausencia de normativa municipal reguladora, en consecuencia se han configurado como normas de ejecución urbanística directamente vinculadas a la Ley.

No obstante, los características de los objetos sometidos a su protección han propiciado que su evolución suponga la superación del carácter de mera norma supletoria, el cual pronto fue olvidado, configurándose como auténticos principios de observación necesario no solo en ausencia de Plan, sino también en el ejercicio de la potestad de planeamiento, por lo que éstas han evolucionado a elementos preordenadores del Plan municipal, lo que no ha impedido que en algunos casos sigan manteniendo su mero carácter supletorio así como de norma de ejecución urbanística directamente emanada de la ley.

El ejercicio de estas funciones encomendadas a las Normas, cuya finalidad es reglada y consistente en el otorgamiento o no de los derechos edificatorios y sobre las que en consecuencia no puede afirmarse la existencia de una discrecionalidad «volitiva», exigen que la estructura normativa de la misma contenga y contemple diversos conceptos jurídicos indeterminados que por la finalidad otorgada es posible, en principio, afirmar que deben dar lugar a una única y exclusiva solución en cada caso, pero que muy pronto la jurisprudencia debió reconocer la existencia de un «halo o zona de incertidumbre», dentro de la cual la Administración dispone de un ámbito de decisión, el cual no supone la existencia de una potestad discrecionalidad sino de un ámbito de libertad de configuración entre la zona positiva y negativa del concepto y responde por tanto no a una función meramente «cognoscitiva», sino «volitiva» dentro de la zona de incertidumbre y mediante el cual se procede a la integración de los supuestos de hechos base de la aplicación de la Norma, la limitación de esa zona de incertidumbre corresponde al Planeamiento mediante el cual la Administración concreta el ámbito de decisión que la Norma le otorga.

La aplicación a las Normas de Aplicación Directa de conceptos jurídicos indeterminados implica que el ámbito de discrecionalidad otorgada al operador jurídico se concreta en la capacidad que dispone la Administración para integrar el supuesto de hecho mediante la incorporación a los elementos de certeza positiva o negativa de aquellos elementos de libre decisión que pueden ubicarse dentro del halo o zona de incertidumbre de los conceptos jurídicos aplicados, las Normas en consecuencia son un claro ejemplo que la dicotomía planteada entre discrecionalidad administrativa y conceptos jurídicos indeterminados no es tan acusada como algu- 
nos autores mantienen y que hablamos mas bien de una diferencia cuantitativa mas que cualitativa.

En este sentido, puede concluirse el incremento de la importancia que la LOTRUSC confiere a las Normas de Aplicación Directa frente al sistema anterior y frente al resto de las normativas de las CC.AA, lo que se caracteriza no solo por su posición dentro del Texto normativo, sino también por el incremento cuantitativo de las mismas frente a la normativa anterior y por el reiterado establecimiento de su carácter imperativo frente al Planeamiento tal como es recogido en su exposición de motivos.

De lo que hemos expuesto hasta la fecha es fácil desprender la existencia de diversos cometidos en las Normas de Aplicación Directa recogidas en la LOTRUSC:

En primer lugar, las Normas contienen una ordenación detallada básica de la ejecución urbanística directamente vinculada a la Ley que permite a los propietarios plasmar sus derechos dominicales en ausencia de Plan y por tanto directamente vinculados en actos de ejecución a una norma legal.

En segundo lugar, las Normas de Aplicación Directa establecen límites directos al planificador en cuanto a las posibles soluciones o alternativas que puede establecer el planeamiento, obligando al mismo a la fijación de determinadas soluciones y a la justificación adecuada de la obtención de los objetivos perseguidos, puede decirse en suma que las Normas suponen una clara limitación a la capacidad de decisión del planificador, limitación que se produce por la necesidad de alcanzar lo que la LOTRUSC ha fijado como objetivos concretos en los que se plasma el interés público.

En tercer lugar, y vinculado con los dos anteriores, las Normas tienen por objeto establecer una ordenación subsidiaria en caso de imprevisión del Planeamiento.

A la vista de las funciones descritas cobran cada vez mas sentido y aplicación las Normas de Aplicación Directa como concretas limitaciones de la potestad de planeamiento por el legislador sectorial y que afecta al ámbito de la Autonomía municipal en la medida que prefigura las soluciones urbanísticas, no sectoriales, desde una norma legal, se articula por tanto como elemento de limitación de la discrecionalidad administrativa mediante el establecimiento de una densidad normativa que limita el campo de decisión y que a la vez posibilita el control de la discrecionalidad de la decisión municipal de establecimiento de un concreto modelo territorial al atribuir al órgano juzgador los elementos de decisión adecua- 
dos que posibiliten la adopción de una decisión basada exclusivamente en derecho.

El ámbito de autonomía municipal constitucionalmente reconocido a los municipios exige que estos, no obstante, no se encuentren sometidos en su control autonómico, en cuanto a la aplicación de las Normas de Aplicación Directa, a un mero criterio de oportunidad, o con un ámbito de actuación mayor que el que pueda desprenderse del resto de los conceptos urbanísticos, a tal efecto la ponderación de los intereses municipales y supramunicipales en juego exigen limitar la actuación de la Comunidad Autónoma al control de los que tiene atribuidos y en todo caso no priva a la misma de su deber de completar los contenidos de la decisión que se opongan a las resoluciones municipales, pues obviamente la Comunidad Autónoma debe necesariamente efectuar el mismo criterio de integración de los conceptos jurídicos indeterminados, y del halo de indeterminación que los mismos conllevan, al objeto de fijar la motivación de la solución adoptada. 